Reconfiguración territorial y mercados de tierras rurales

\title{
Procesos de avance territorial del capitalismo en Mendoza (Argentina): Transformaciones en la ganadería al quiebre del siglo XXI
}

Processes of Territorial Advance of Capitalism in Mendoza (Argentina): Transformations of Livestock Farming in the Turn of the 21st Century

Processos de avance territorial do capitalismo em Mendoza (Argentina): Transformações na pecuária no inicio do s. XXI

Laura María Torres*

Daniela Pessolano**

Romina Giselle Sales ${ }^{* * *}$

Recibido: 9 de enero 2014

Aprobado: 14 de marzo de 2014

Doi: dx.doi.org/10.12804/territ30.2014.02

Para citar este artículo:

Torres L. M., Pessolano, D. y Sales R. G. Procesos de avance territorial del capitalismo en Mendoza (Argentina): transformaciones en la ganadería al quiebre del siglo XXI. Territorios, 30, 39-67. doi: dx.doi.org/10.12804/ territ30.2014.02

* Licenciada en Trabajo Social, egresada de la Facultad de Ciencias Politicas y Sociales, Universidad Nacional de Cuyo, Argentina. Doctorado en Antropología e Historia bajo el programa Relaciones Interétnicas en América Latina: Presente y Pasado. Universidad de Sevilla, España. Actualmente se desempeña como investigadora en el Consejo Nacional de Investigaciones Científicas y Técnicas (Conicet). Correo electrónico:ltorres@mendoza-conicet.gob.ar

** Licenciada en Trabajo Social. Facultad de Ciencias Politicas y Sociales, Universidad Nacional de Cuyo, Argentina. Doctoranda en Ciencias Sociales, con mención en Trabajo Social, Facultad de Ciencias Sociales y Politicas, Univer- $\Rightarrow$ 
Palabras clave

Transformaciones territoriales, expansión capitalista, ruralidad, ganadería, Mendoza.

Keywords

Territorial transformations, capitalist expansion, rurality, livestock production, Mendoza.

Palavras-chave

Transformações territoriais, expansão capitalista, ruralidade, pecuária, Mendoza.

\section{territarias 30}

\section{RESUMEN}

A partir de los años setenta y especialmente luego de los noventa, los territorios rurales de Argentina surcan profundas transformaciones estructurales. El nuevo modelo de acumulación asociado al auge del neoliberalismo traducirá en la implantación de un modelo financiero de agricultura fuertemente apoyado en la producción de commodities destinadas a la exportación.

La producción sojera, considerada en Argentina un caso paradigmático de avance del capitalismo sobre la ruralidad, tendrá hondas repercusiones primero en territorios pampeanos y, luego, en territorios extrapampeanos que constituyeron su segundo frente de expansión. Sobre el oeste nacional, los territorios mendocinos y cada una de las actividades productivas que componen su ruralidad, experimentarán procesos de transformación y reconversión productiva de distinta envergadura.

En este contexto, se analizan las transformaciones que se registran en la actividad ganadera de Mendoza en función del análisis exhaustivo de datos estadísticos y considerando prioritariamente una prolongación temporal de 20 años (1988-2008).

La hipótesis señala que la ganadería mendocina acusa cambios que se corresponden con tendencias a la concentración de la producción, la introducción de tecnologías y el ingreso de capitales extranjeros, de lo que se desprende la desaparición de aquellos actores sociales que no computan como agentes competitivos en el sistema económico vigente.

\section{ABSTRACT}

Since the 70s, and especially after the 90s, rural territories in Argentina undergo deep structural transformations. The new model of accumulation associated with the rise of neoliberalism will result in establishment of an agricultural financial model heavily relying on producing commodities for export.

Soybean production, regarded in Argentina as a paradigmatic case of the advance of capitalism on rurality, will have profound repercussions, first on Pampean territories and afterwards on extraPampas areas which constituted a second expansion front. On the country's west, Mendoza's territories, and each of the productive activities that make up their rurality, will experience productive transformation and/or restructuring processes of varying magnitudes.

In this context, we analyze the transformations occurred in livestock farming in Mendoza, based on exhaustive analysis of statistical data and giving priority to a time span of 20 years (1988-2008).

The hypothesis points out that Mendoza's livestock production shows changes that match the trends towards concentration of production, introduction of technologies and inflows of foreign capital, from which follows disappearance of those social actors that do not count as competitive agents in the current economic system.

\section{RESUMO}

A partir dos anos 70 e especialmente depois dos 90, os territórios rurais da Argentina sulcam profundas transformações estruturais. O novo modelo de acumulação associado ao auge do neoliberalismo traduzirá na implantação de um modelo financeiro de agricultura fortemente apoiado na produção de commodities destinadas à exportação. 
A produção de soja, considerada na Argentina um caso paradigmático de avance do capitalismo sobre a ruralidade, terá profundas repercussões primeiro em territórios pampeanos e depois, em territórios extra-pampeanos que constituíram seu segundo frente de expansão. Sobre o oeste nacional, os territórios de Mendoza e cada uma das atividades produtivas que compõem sua ruralidade, experimentarão processos de transformação e/ou reconversão produtiva de envergadura diferente.

Neste contexto, analisam-se as transformações que se registram na atividade pecuária de Mendoza em função da análise exaustiva de dados estadísticos e considerando prioritariamente uma prolongação temporal de 20 anos (1988-2008).

A hipótese assinala que a pecuária de Mendoza acusa mudanças que se correspondem com tendências à concentração da produção, a introdução de tecnologias e o ingresso de capitais estrangeiros, do que se desprende a desaparição de aqueles atores sociais que não computam como agentes competitivos no sistema econômico vigente.

\section{Cambios del modelo de acumulación. Territorios rurales pampeanos y extrapampeanos y procesos de agriculturización ${ }^{1}$}

La década del setenta asiste a una renovación del sistema capitalista que se extiende hasta nuestros días, caracterizada como procesos de globalización. En su carácter complejo y multifacético, esta etapa propició la expansión de las relaciones capitalistas de mercado, dando paso a la mercantilización de distintas esferas de la actividad económica, social y cultural (Glyn y Sutcliffe, 1992 en Teubal, 2001). En términos generales, significó una pérdida de gobernabilidad por parte de los estados-nación ante el fuerte predominio de grandes empresas trasnacionales y el pensamiento único que sostiene sus intereses (McMichael y Myhre, 1991; Ramonet, 1995 en Teubal, 2001).

En América Latina y Argentina, el nuevo modelo de acumulación, plenamente asociado al auge del neoliberalismo, implicará la apertura de la economía, la desre- gulación y liberalización de los mercados y la aplicación de políticas orientadas a la flexibilización y precarización laboral (Gras y Hernández, 2009).

Los sistemas agrarios y agroalimentarios de los países latinoamericanos no permanecerán al margen de esta cascada de transformaciones y se orientarán, con particular fuerza en la década del noventa, a un modelo financiero de agricultura (Gras, 2005 ) fuertemente apoyado en la producción de commodities destinadas a la exportación (Rofman, 2012; Teubal, 2001; Kay, 1995; Manzanal, 2006; Gras y Hernández, 2009). Más allá de que algunos actores y sectores de la producción, vean en estos procesos de cambio, alentadores signos de asimilación del agro a nuevos estándares de productividad o renovados ingresos por exportaciones que refrescan las arcas del Estado para financiar la lucha contra la pobreza (Gudynas, 2012), el nuevo modelo tendrá un carácter fuertemente concentrador y excluyente que creará nuevas condiciones de polarización social. De un lado, sidad Nacional de Cuyo. Becaria doctoral del Consejo Nacional de Investigaciones Científicas y Técnicas (Conicet) con lugar de trabajo en el Iadiza, CCT Mendoza, Conicet. Correo electrónico: dpessolano@ mendoza-conicet.gob.ar

*** Arquitecta. Facultad de Arquitectura, Diseño y Urbanismo, Universidad de Mendoza, Argentina. Doctoranda en Arquitectura y Urbanismo, Universidad Nacional de San Juan, Argentina, Facultad de Arquitectura, Urbanismo y Diseño. Becaria doctoraldel Consejo Nacional de Investigaciones Cientificas y Técnicas (Conicet) con lugar de trabajo en el Iadiza, CСT Mendoza, Conicet. Correo electrónico: rsales@ mendoza-conicet.gob.ar

${ }^{1}$ El presente artículo se deriva de un proyecto de investigación titulado "Procesos de expansión del capital y reconversión productiva en espacios rurales de Mendoza a principios del s. XXI" dependiente de la Secretaria de Ciencia, Técnica y Posgrado de la Universidad Nacional de Cuyo.

territarias 30 41 
quedarán entonces los medianos y pequeños productores del agro y los campesinos y trabajadores rurales sin tierra, mientras en el otro extremo se ubicarán las grandes corporaciones trasnacionales que controlan el mercado mundial de producción agroalimentaria, el mercado de insumos agropecuarios (semillas, fertilizantes y pesticidas), el procesamiento industrial y las cadenas de comercialización (Teubal, 2001).

La tendencia común en los países latinoamericanos a la producción de alimentos de exportación no tradicionales, redundará, por su parte, en el progresivo reemplazo de la producción de alimentos básicos para la población local y en la incorporación masiva de agroquímicos, particularmente pesticidas. Como bien analiza Teubal “...frente a la caída de los precios del café, la banana, el azúcar y el algodón que se produce en los ' 80 , los gobiernos locales fueron inducidos a reemplazar estas exportaciones tradicionales por otras de alto valor agregado, por ejemplo, mangos, kiwis, flores y otras frutas y hortalizas" (2001, p. 49).

En el caso argentino, la paradoja de un país ‘desnutrido' que se piensa como 'granero del mundo' (Pengue, 2004) hallará su ejemplo paradigmático en la producción de soja, principal producto agrícola de exportación del nuevo milenio, responsable de la desaparición de paisajes enteros y de profundas transformaciones en la estructura agraria, tanto pampeana como extrapampeana.

En los territorios pampeanos de Arterritarias 30 42 gentina, es decir allí donde las empresas trasnacionales y los pool de siembra eri- gieron el primer bastión territorializador de la soja, los datos del presente muestran una drástica retracción del empleo rural disponible para los trabajadores rurales y procesos de desplazamiento y arrinconamiento de los pequeños productores (Teubal, 2001; Reboratti, 2006; Gras y Hernández, 2009; Domínguez y Sabatino 2006). Cuando no resultaron objeto de desplazamiento forzado (Domínguez, 2003), las nuevas condiciones de territorialización del capital estimularon la proletarización o transformación de los pequeños productores en cuentapropistas urbanos, mientras en otros casos, la estrategia de alquiler de parte o la totalidad de sus propiedades, los convirtió en productores-arrendatarios. Impresas sobre un agro dual, las tendencias del presente se orientan a la creación de una "agricultura sin agricultores [y de una] ganadería sin productores ganaderos" (Domínguez y Orsini, 2009). Por su parte, los efectos ambientales del proceso de avance de la soja son verdaderamente preocupantes. Además del reemplazo de cultivos tradicionales, homogeneización agrícola e intensificación en el uso del suelo, en las regiones extrapampeanas el avance sojero ha supuesto la acentuación de las prácticas de desmonte y la erosión de las tecnologías productivas regionales (Aizen, Garibaldi y Dondo, 2009; Manuel-Navarrete et al, 2005; Viglizzo y Jobbágy, 2010).

En forma paralela, los territorios extrapampeanos que habían quedado fuera del mapa de las 'economías regionales exitosas' y acusaban un ritmo más lento de penetración de las relacionales sociales capitalistas 
(Hocsman y Preda, 2005; González y Román, 2009; Comerci, 2010; Cáceres et al, 2009; Paz, 2011) se hallan en el presente sujetos a un renovado proceso de revalorización por parte del capital, orientado a volcar al mercado una larga cadena de materias primas y servicios ecosistémicos para mantener o acrecentar las tasas de rentabilidad (Galafassi, 2012). En este contexto, territorios que habían quedado en manos del campesinado y muchos de los cuales eran objeto de apropiación en el marco de sistemas de uso común de los recursos territoriales, se constituyen en espacios altamente apetecibles para la instalación de nuevos proyectos empresariales, muchos de ellos en manos de capitales extranjeros, algunos orientados a la producción sojera; otros a acoger los cultivos y actividades productivas que esta desplaza. Por esta vía y alejándose definitivamente de los presagios de los partidarios de la modernización, el maldesarrollo (Tortosa, 2011), asociado a la mercantilización del territorio, estimula el vaciamiento de los espacios rurales, tanto en términos de población como de funciones y actividades económico-productivas (Rofman, 2012) y, en lugar de asistirse a la consolidación de un mercado único integralmente globalizado (Albuquerque, 1999), se observa la aparición de núcleos de actividades fuertemente conectadas con el mercado mundial en coexistencia con 'vulnerabilidades selectivas', que "exponen de manera desigual a las poblaciones a los efectos del desempleo, la degradación de los niveles de vida, la pérdida de recursos y de opciones y calidades ambientales"
(Harvey, 2003 en Valenzuela, 2005, s. n.). Finalmente, pero no menos importante, el uso extractivo del territorio, vale decir, su apropiación trocada en productos $\mathrm{co}^{-}$ mercializables desatendiendo la cola de desechos que las actividades generan, plantea la emergencia de verdaderos conflictos ecológicos distributivos que suponen una desigual afectación de las poblaciones y territorios del uso que la economía hace de la naturaleza (Martínez-Alier, 2004).

Al pie del sistema montañoso de la cordillera de los Andes, la provincia de Mendoza exhibe un apretado régimen de precipitaciones $(200 \mathrm{~mm} /$ anules $)$ y un balance hídrico que la ubica dentro de los climas áridos e hiperáridos de Argentina. Ante los requerimientos de acompañar la inserción de Argentina en los mercados internacionales (Katz y Kosacoff, 1989) con productos que no entraran en competencia con los de origen pampeano, Mendoza consolidó a lo largo del siglo Xx una fuerte industria vitivinícola, que desplegó prolijos paños de vides dependientes del riego. Por fuera de los territorios irrigados que albergan a la vitivinicultura y que representan no más del 4,8\% del territorio provincial (APOT, 2013), los espacios no irrigados acogen la producción hidrocarburífera y ganadera, entre otras de menor importancia relativa.

Si bien a partir del estudio de los procesos de avance territorial del capitalismo en regiones extrapampeanas, algunos autores indican que los territorios del oeste nacional receptan los stocks ganaderos que la soja desplaza y que este proceso se acompaña del ingreso de nuevas lógicas empre- territarias 30 
sariales asociadas a la ganadería capitalista, hasta el momento no se dispone de trabajos que hayan indagado estas tendencias en la provincia de Mendoza. Esta situación persiste aun cuando la ganadería computa en Mendoza como una actividad productiva de larga prolongación temporal, se despliega sobre amplias superficies, permite el desarrollo empresarial y da sustento a una importante fracción del campesinado mendocino.

La bibliografía existente a nivel nacional en relación con procesos de reconversión productiva y avance de la frontera agropecuaria es amplia y diversa, pero se halla prioritariamente concentrada en la región pampeana $y$, dentro de las extrapampeanas, en aquellas que configuran los nuevos destinos de la soja (NEA y NOA) (Domínguez, Orsini y Beltrán, 2012; Viglizzo y Jobbágy, 2010; Azcuy y Ortega, 2009; Rofman, 2012). Los trabajos disponibles para Mendoza, por su parte, si bien reconocen los efectos del desplazamiento de la ganadería hacia el este provincial, se hallan menos interesados por el estudio de los efectos socioambientales que inducen estos procesos de cambio y se orientan más bien a considerar las posibilidades de aumentar el stock ganadero, y con él, la producción de carne mediante la introducción de tecnología, capital y asistencia técnica (Fanjul, 2012; Grünwaldt y Guevara, 2011). En otras palabras, denotan un talante productivista más acuciado que busca acrecentar el perfil empresarial de las explotaciones sin incorporar reflexiones acerca de para qué y para quiénes son los beneficios eco- nómicos resultantes. Los trabajos que en Mendoza han hecho foco en los procesos de reconversión productiva por los que surca la provincia al quiebre del siglo XXI, se han centrado de manera prioritaria en la actividad vitivinícola, retaceando atención, tanto a las actividades agrícolas que desbordan a la vitivinicultura como a las que tienen lugar en los territorios no irrigados (Torres, 2006). En definitiva, más allá de los trabajos de corte productivista que intentan asimilar a Mendoza al concierto de las provincias ganaderas eficientes, no se dispone de trabajos que hayan podido captar las características y magnitudes de los cambios en el seno de la ganadería, menos aun que lo hagan en vínculo con las dinámicas de cambio estructural por las que surca la ruralidad argentina.

En virtud de los vacíos temáticos del presente como también atendiendo a la urgencia que estos recorridos tienen en una provincia que posee más del $90 \%$ de su territorio en condición de no irrigado, este trabajo se orienta a analizar las transformaciones que induce el avance expansivo del capital sobre las tierras secas no irrigadas en la ruralidad de Mendoza, considerando específicamente los cambios acaecidos en la producción ganadera en un período de 20 años (1988-2008). El análisis, fuertemente apoyado en datos estadísticos, parte, sin embargo, de presupuestos teóricos que problematizan los criterios de productividad emanados de la economía neoclásica.

Guiado por el objetivo antes enunciado, este trabajo considera datos oficiales del período 1988-2008 y recurre al uso de información más actualizada toda vez que 
resulta posible. Se revisan los censos nacionales agropecuarios 1988, 2002 y 2008, además de datos elaborados por el Servicio Nacional de Sanidad y Calidad Agroalimentaria (Senasa), la Dirección Provincial de Desarrollo Territorial (DDT) y el Ministerio de Justicia y Derechos Humanos de la Nación.

Dentro de las actividades pecuarias, se consideran con especial detalle la ganadería bovina y caprina; la primera porque su análisis otorga indicios directos acerca de la posibilidad o no de referirse a procesos de bovinización en Mendoza y la segunda por la significación cuantitativa que ostenta a nivel provincial y nacional ${ }^{3} \mathrm{y}$ por cuanto se vincula a explotaciones de pequeños productores y campesinos, fundamentalmente. Para finalizar, las categorías de análisis que se indagan se refieren a: cantidad de Explotaciones agropecuarias (en adelante EAP), por escala de extensión, superficie de las explotaciones, cabezas de ganado, EAP por tamaño de rodeo, tipo de rodeo, prácticas de manejo y porcentaje de extranjerización de la tierra en la provincia.

La hipótesis de trabajo sobre la que se vertebran estos recorridos señala que las actividades ganaderas que se desarrollan en Mendoza registran cambios en los últimos años que pueden ser asociados al proceso de sojización y que se ven reflejados en un aumento de las existencias ganaderas provinciales. Dado por su parte que estas transformaciones fijan en clave local un proceso de alcance más general - procesos de bovinización- se corresponden con tendencias a favor de la concentración de la producción, la introducción de tecnologías y con el ingreso a la actividad de capitales extranjeros, de lo que se desprende en Mendoza la desaparición de aquellos actores sociales que no computan como agentes competitivos en el sistema económico vigente $y$, con ello, la mercantilización creciente de los recursos naturales.

\section{La producción ganadera en Mendoza. Una aproximación a través de los números}

La producción bovina de Argentina atraviesa profundos procesos de reestructuración o reordenamiento territorial (Azcuy y Ortega, 2009; Rearte, 2010, 2011). Su escasa competitividad relativa respecto de la producción agrícola, constituye el principal elemento causal de la pérdida de quince millones de hectáreas dedicadas a la ganadería ahora en manos de productores de oleaginosas, principalmente de soja (Charvay, 2012; Rearte, 2011). Esto explica que si bien la región pampeana mantiene su preponderancia absoluta como principal concentradora del stock ganadero nacional (68\% para el año 2013), en términos relativos es también la región que más ganado ha perdido, con una caída promedio del stock del $20 \%$ en la última década (Observatorio Ganadero, 2013). Paralelamente, el NEA ha incrementado su participación en el stock nacional alcanzando el 19\% en 2013 (Observatorio Ganadero, 2013). Ambas regiones son las que más existencias ganaderas concentran, situación que se vuelve comprensible no solo en virtud de
${ }^{2}$ Los datos censales correspondientes al Censo Nacional Agropecuario 2008 se deben considerar con cautela por cuanto se trata de datos provisorios.

${ }^{3}$ De acuerdo con el Senasa, Mendoza constituye la principal productora de caprinos a nivel nacional, con 776196 cabezas al año 2013. Le siguen en orden de importancia Neuquén (655490) y Santiago del Estero (535739).

territarias 30

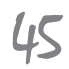


las condiciones climáticas favorables que las caracterizan sino también por el posicionamiento estratégico que ostentan en relación a los puertos y a los grandes centros de consumo nacional (Fanjul, 2012).

En los territorios extrapampeanos, los procesos de bovinización (Hocsman y Preda, 2005) suponen un amplio entramado de transformaciones, entre las que se destacan el aumento de las existencias ganaderas, el ingreso de nuevas modalidades y perfiles productivos (Rofman, 2012) y crecientes tendencias hacia la extranjerización y concentración de la tierra. Por su parte, estas dinámicas se acompañan de cambios tecnológicos en la terminación del ganado, que se pueden ver reflejados en el pasaje del sistema pastoril con suplementación a la forma de confinamiento (feed lot) (Milano, 2011).

Los datos disponibles para la provincia de Mendoza muestran algunas tendencias comunes a otros territorios extrapampeanos argentinos, al mismo tiempo que expresan ciertas particularidades.

Autores interesados en el análisis de los cambios socio-territoriales que traen consigo los procesos de avance del capitalismo en los espacios rurales de Argentina, señalan su profunda correspondencia con la desaparición de las pequeñas explotaciones campesinas (Cáceres et al, 2009; Paz, 2011). Estas observaciones parten de considerar la relación existente entre la cantidad de explotaciones agropecuarias y sus superficies e indican una caída en el número

\section{territarias 30} 46
Considerada en su conjunto, entre 1974 y 2008 la ruralidad de Mendoza acusa una disminución del orden del $32 \%$ en el número de explotaciones agropecuarias con límites definidos y del orden de 19\% en la superficie destinada a usos agrícolas y ganaderos (figura 1).

A lo largo del período intercensal 1988-2008 se incrementa también el tamaño promedio de las explotaciones agropecuarias, con una caída del peso relativo de las unidades de hasta 200 hectáreas del $35 \%$ y el crecimiento de las unidades ubicadas en los estratos intermedios y grandes (tabla 1, figura 2).

Aislada la actividad ganadera de las otras actividades productivas que componen la ruralidad de Mendoza y aun considerando los datos expuestos anteriormente, el número de cabezas bovinas crece de manera constante en los últimos tres períodos intercensales (1988, 2002, 2008). En este sentido, si bien Mendoza no logra remontar las pérdidas en los stocks que registra la región pampeana, junto a las provincias del NOA, NEA y a las restantes que integran Cuyo (San Juan y San Luis), entre 1988 y 2008 incrementa sus existencias bovinas (47\%) y caprinas (6\%). Por su parte, estos procesos se corresponden con una disminución en el número de EAP centradas en la producción pecuaria (bovina y caprina) (tabla 2).

Entre 2002 y 2008, la cantidad de explotaciones agropecuarias que poseen existencias bovinas disminuye un $15 \%$. Por su parte, esta caída se distribuye de manera diferencial entre las explotaciones agrope- 
Figura 1. Cantidad y la superficie de EAP con límites definidos

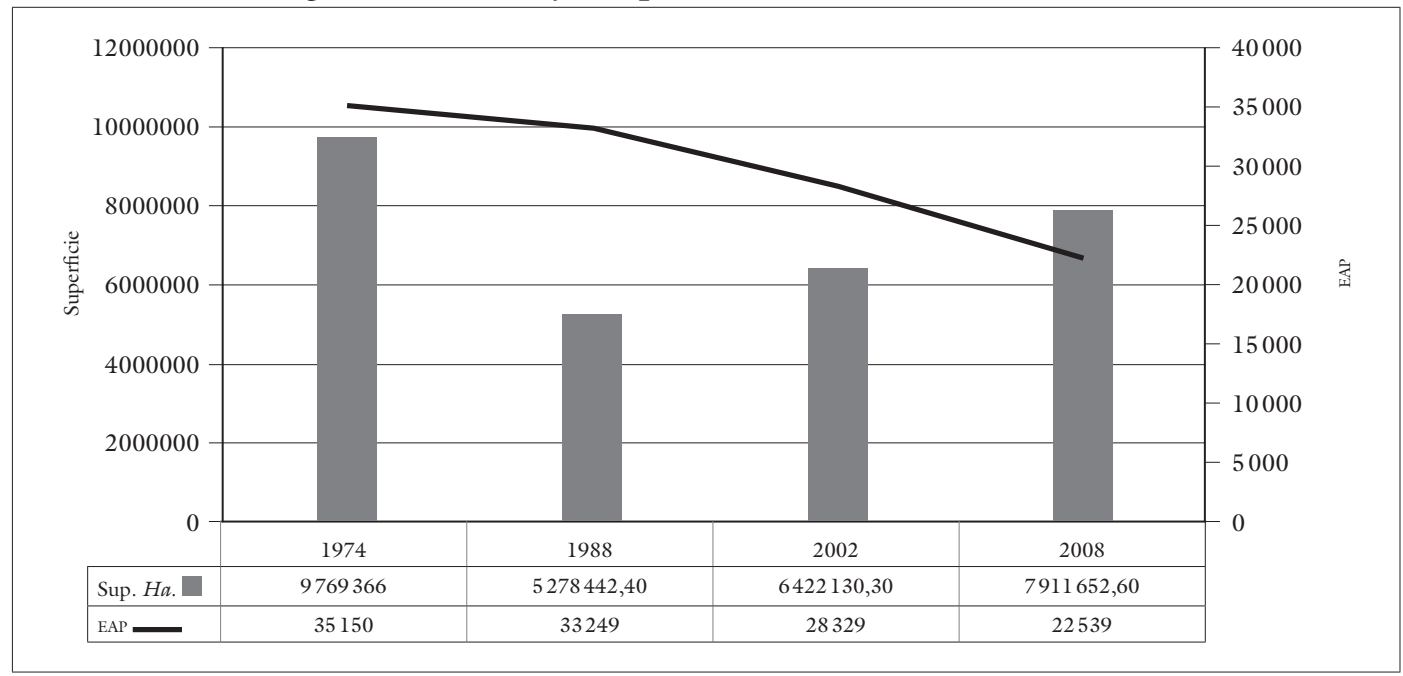

Evolución intercensal 1947, 1988, 2002 y 2008. Mendoza

Fuente: Elaboración propia con base en datos del Censo Ganadero provincial (1974), CNA 1988, 2002 y 2008. Indec.

Tabla 1. Cantidad de EAP con límites definidos por escala de extensión.

Variación relativa 1988-2008. Mendoza

Escala de extensión de las EAP $(b a)$

\begin{tabular}{|c|c|c|c|c|c|c|c|c|c|c|}
\hline & CNA & $\begin{array}{l}\text { Total } \\
\text { EAP }\end{array}$ & $\begin{array}{c}\text { Hasta } \\
25\end{array}$ & $\begin{array}{l}\text { De } 25,1 \\
\text { a } 100\end{array}$ & $\begin{array}{c}\text { De } \\
100,1 \text { a } \\
200\end{array}$ & $\begin{array}{c}\text { De } \\
200,1 \text { a } \\
500\end{array}$ & $\begin{array}{c}\text { De } \\
500,1 \text { a } \\
1000\end{array}$ & $\begin{array}{c}\text { De } \\
1000,1 \\
\text { a } 5000\end{array}$ & $\begin{array}{c}\text { De } \\
5000,1 \\
\text { a } 10000\end{array}$ & $\begin{array}{l}\text { Más de } \\
10000\end{array}$ \\
\hline \multirow{4}{*}{ 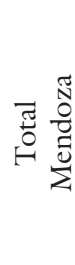 } & 1988 & 33249 & 27717 & 4026 & 564 & 286 & 113 & 299 & 135 & 109 \\
\hline & 2002 & 28329 & 22821 & 3620 & 609 & 313 & 185 & 474 & 163 & 144 \\
\hline & 2008 & 22539 & 17276 & 3156 & 529 & 310 & 202 & 677 & 215 & 174 \\
\hline & $\begin{array}{l}\text { Variación relativa } \\
1988 / 2008\end{array}$ & $-32 \%$ & -38 & $-22 \%$ & $-6 \%$ & $8 \%$ & $78 \%$ & $126 \%$ & $59 \%$ & $59 \%$ \\
\hline
\end{tabular}

Fuente: Elaboración propia en base a datos de los censos nacionales agropecuarios 1988, 2002 y 2008. Indec.

cuarias con y sin límites definidos. Mientras las EAP con límites definidos que poseen ganado bovino disminuyen un $4 \%$ y la cantidad de cabezas bovinas bajo su control, aumentan el 9\%; las EAP sin límites defini- dos disminuyen un $25 \%$ y el ganado que ellas controlan cae un $28 \%$. Así las cosas, aun considerando que las explotaciones sin límites definidos siguen representando un volumen importante $(45 \%$ del total de 
Figura 2. Cantidad de EAP con límites definidos por escala de extensión ( $h a)$. Variación relativa intercensal 1998-2008. Mendoza

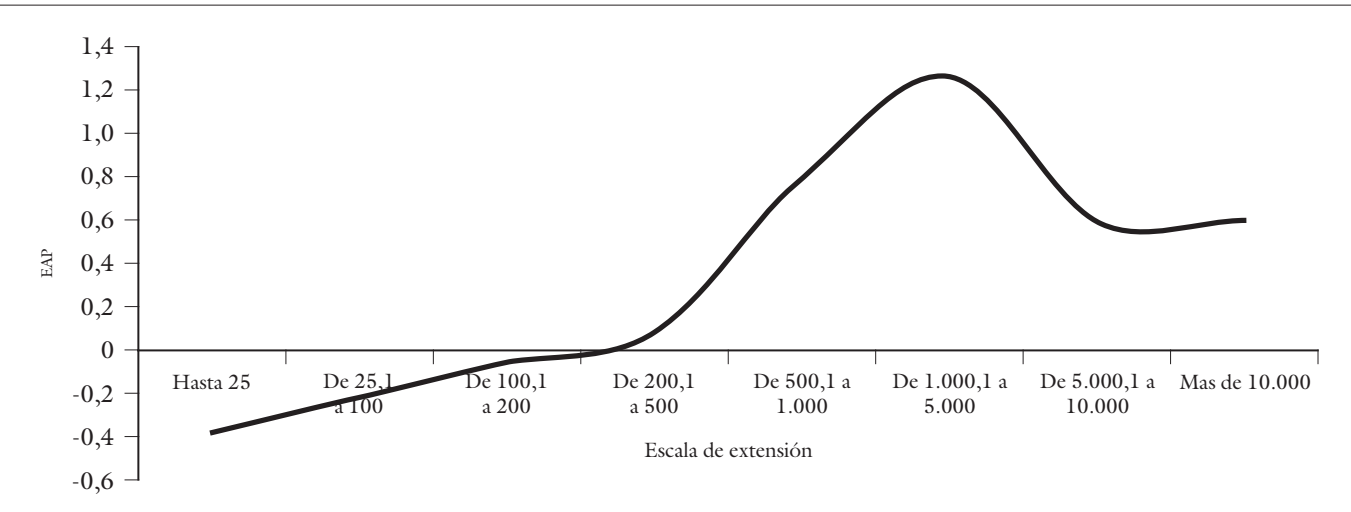

Fuente: Elaboración propia con base en datos CNA 1988, 2008. Indec.

Tabla 2. Ganado bovino y caprino. Explotaciones agropecuarias y cabezas de ganado, por tipo. Mendoza, 1988, 2002 y 2008

\begin{tabular}{|c|c|c|c|c|c|c|c|c|c|}
\hline & \multirow{2}{*}{$\begin{array}{c}\text { CNA } 1988 \\
\text { EAP } \\
\text { Totales }\end{array}$} & \multicolumn{3}{|c|}{$\begin{array}{c}\text { CNA } 2002 \\
\text { EAP }\end{array}$} & \multicolumn{3}{|c|}{$\begin{array}{c}\text { CNA } 2008 \\
\text { EAP }\end{array}$} & \multirow{2}{*}{$\begin{array}{c}\text { Variación } \\
1988 \\
/ 2008\end{array}$} \\
\hline & & & $\begin{array}{c}\text { Con límites } \\
\text { definidos }\end{array}$ & $\begin{array}{l}\text { Sin límites } \\
\text { definidos }\end{array}$ & Totales & $\begin{array}{l}\text { Con límites } \\
\text { definidos }\end{array}$ & $\begin{array}{l}\text { Sin límites } \\
\text { definidos }\end{array}$ & Totales & \\
\hline \multirow{2}{*}{ 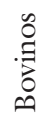 } & EAP & 3327 & 1511 & 1594 & 3105 & 1451 & 1203 & 2654 & $-20 \%$ \\
\hline & Cabezas & 276028 & 305833 & 98877 & 404710 & 336386 & 70808 & 407194 & $47 \%$ \\
\hline \multirow{2}{*}{ 节 } & EAP & 2426 & 664 & 1967 & 2631 & 743 & 1636 & 2379 & $-2 \%$ \\
\hline & Cabezas & 616572 & 123381 & 549053 & 672434 & 207806 & 449982 & 657788 & $6 \%$ \\
\hline
\end{tabular}

Fuente: Elaboración propia con base en datos de los censos nacionales agropecuarios 1988, 2002 y 2008 . Indec.

\section{territarias 30}

explotaciones y ganado, en las sin límites definidos, en su mayoría asociadas a predios campesinos que ostentan ocupaciones precarias (Paz, 2011).

En una mirada atenta a recuperar las particularidades de la producción bovina al interior de la provincia, los departamentos que en 2008 concentraban las mayores exis-
EAP con existencias bovinas en 2008), los datos estarían indicando que, paralelo al aumento de las existencias bovinas y a la disminución en la cantidad de explotaciones agropecuarias dedicadas a la actividad, las existencias ganaderas totales, en crecimiento, se concentran en las explotaciones con límites definidos y las pérdidas de 
tencias eran San Rafael, Malargüe y General Alvear, seguidos por un segundo grupo compuesto por San Carlos, La Paz, Santa Rosa y Lavalle. En 2008, los departamentos sureños contenían el $65 \%$ de las existencias bovinas de la provincia y los siguientes cuatro se repartían un $26 \%$ (mapa 1 ). A excepción de Santa Rosa que acusa una leve disminución en el stock bovino entre
1988 y 2008 (-6\%), los departamentos de mayor vocación ganadera experimentan incrementos en las existencias bovinas. Los casos más llamativos son San Carlos, con un aumento del 397\%, San Rafael (98\%) y Malargüe (89\%). En el este mendocino, las existencias ganaderas en Lavalle y La Paz aumentan el $44 \%$ y $29 \%$, respectivamente (tabla 3 , carta 1 ).

Tabla 3. Existencias ganaderas bovinas por departamento. Mendoza, 1988, 2002 y 2008

\begin{tabular}{|c|c|c|c|c|}
\hline & $\begin{array}{c}\text { Existencias ganaderas } \\
\text { bovinas CNA } 1988\end{array}$ & $\begin{array}{c}\text { Existencias ganaderas } \\
\text { bovinas CNA } 2002\end{array}$ & $\begin{array}{c}\text { Existencias ganaderas } \\
\text { bovinas CNA } 2008\end{array}$ & $\begin{array}{c}\text { Variación porcentual } \\
1988 / 2008\end{array}$ \\
\hline Total & 266606 & 404710 & 407194 & $53 \%$ \\
\hline Capital & - & - & - & - \\
\hline General Alvear & 64425 & 72628 & 66776 & $4 \%$ \\
\hline Godoy Cruz & 81 & 45 & 77 & $-5 \%$ \\
\hline Guaymallén & 472 & 272 & 71 & $-85 \%$ \\
\hline Junín & 456 & 83 & 34 & $-93 \%$ \\
\hline La Paz & 23933 & 40677 & 30942 & $29 \%$ \\
\hline Las Heras & 4842 & 5241 & 4497 & $-7 \%$ \\
\hline Lavalle & 12883 & 12469 & 18513 & $44 \%$ \\
\hline Luján de Cuyo & 1989 & 3522 & 3802 & $91 \%$ \\
\hline Maipú & 3057 & 190 & 3336 & $9 \%$ \\
\hline Malargüe & 37938 & 62247 & 71634 & $89 \%$ \\
\hline Rivadavia & 5610 & 7175 & 4198 & $-25 \%$ \\
\hline San Carlos & 7932 & 29807 & 39383 & $397 \%$ \\
\hline San Martín & 951 & 803 & 967 & $2 \%$ \\
\hline San Rafael & 64762 & 130294 & 128062 & $98 \%$ \\
\hline Santa Rosa & 26022 & 26579 & 24441 & $-6 \%$ \\
\hline Tunuyán & 4522 & 5886 & 5323 & $18 \%$ \\
\hline Tupungato & 6731 & 6792 & 5138 & $-24 \%$ \\
\hline
\end{tabular}

Fuente: Elaboración propia con base en datos de los censos nacionales agropecuarios 1988, 2002 y 2008 . Indec. 


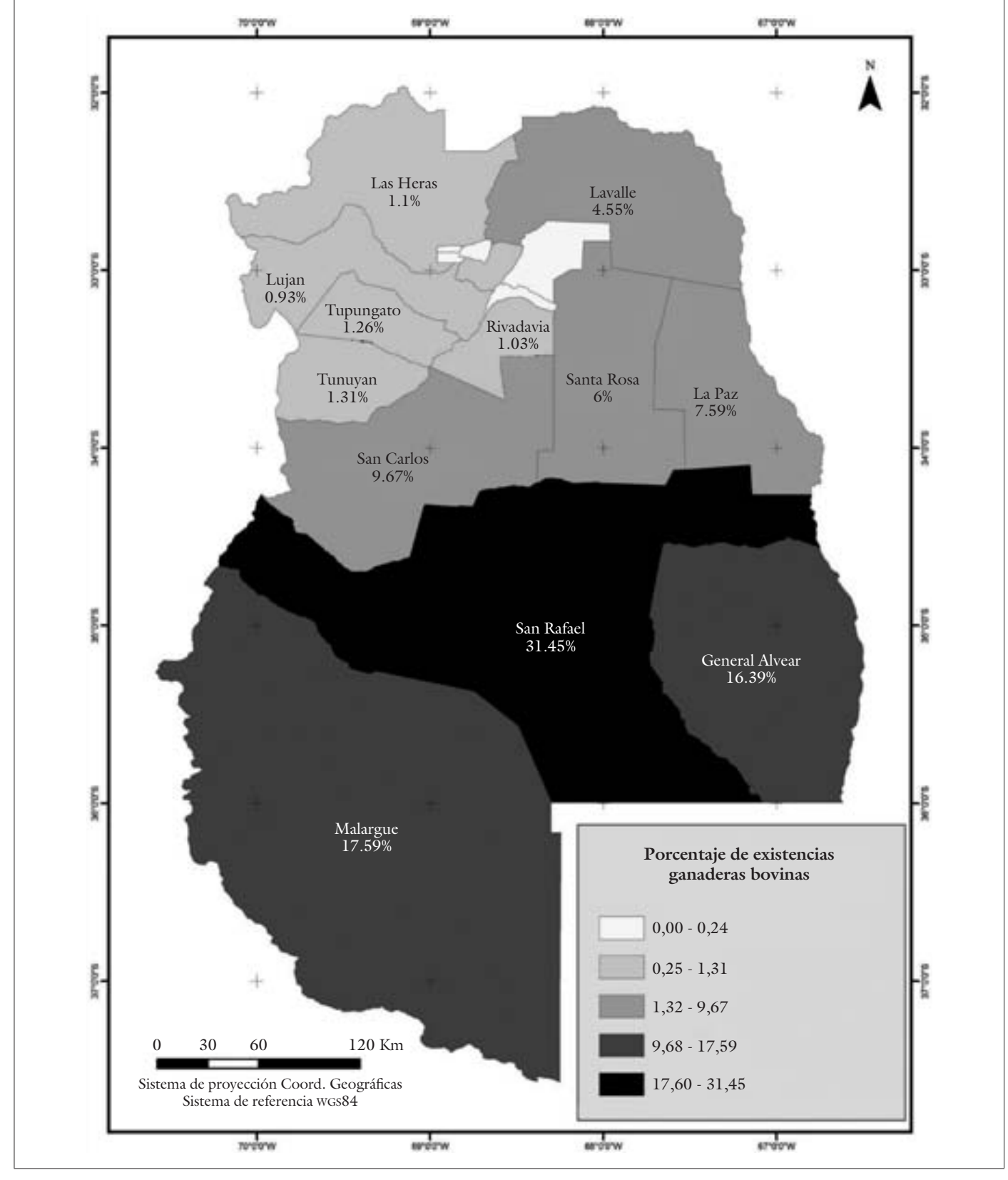


Por su parte, mientras entre 1988 y 2008 las explotaciones agropecuarias más pequeñas (hasta 25 cabezas) caen (-67\%), las que computan hasta 50 cabezas prácticamente se mantienen y las de mayores dimensiones (más de 51 y hasta 2000) aumentan $(64 \%)$, los mayores crecimientos en el stock ganadero tienden a concentrarse entre las explotaciones que se posicionan más allá de las 200 cabezas y, en especial, entre las que poseen entre 500 y $2000 \mathrm{ca}$ bezas (figura 3 ), es decir entre aquellas que quedan fuera de las que pueden calificarse como pequeñas (Obschatko et al, 2007). En este sentido, en el año 2008 se observa que las explotaciones agropecuarias que se ubican por debajo de las 200 cabezas representan el $82 \%$ del total y contienen el $32 \%$ del stock, mientras las EAP por encima de las 200 cabezas representan el 18\% del total y contienen el $68 \%$ del stock. La figura 3 permite visualizar estas tendencias a lo largo de 20 años, detectándose para 2008 concentración del stock entre las explotaciones de mayor tamaño.

Separados del total provincial los departamentos que concentran las mayores existencias bovinas, ${ }^{4}$ las tendencias antes indicadas se reiteran y profundizan. En este sentido, las variaciones en la cantidad de EAP y cabezas bovinas que se registran entre 1988 y 2008 (figura 4) permiten advertir una fuerte caída de las explotaciones ganaderas más pequeñas y el aumento de las EAP de mayores dimensiones, al mismo tiempo que la concentración del stock entre

Figura 3. Bovinos. Cantidad de cabezas y EAP según tamaño del rodeo. Mendoza 1988/2008

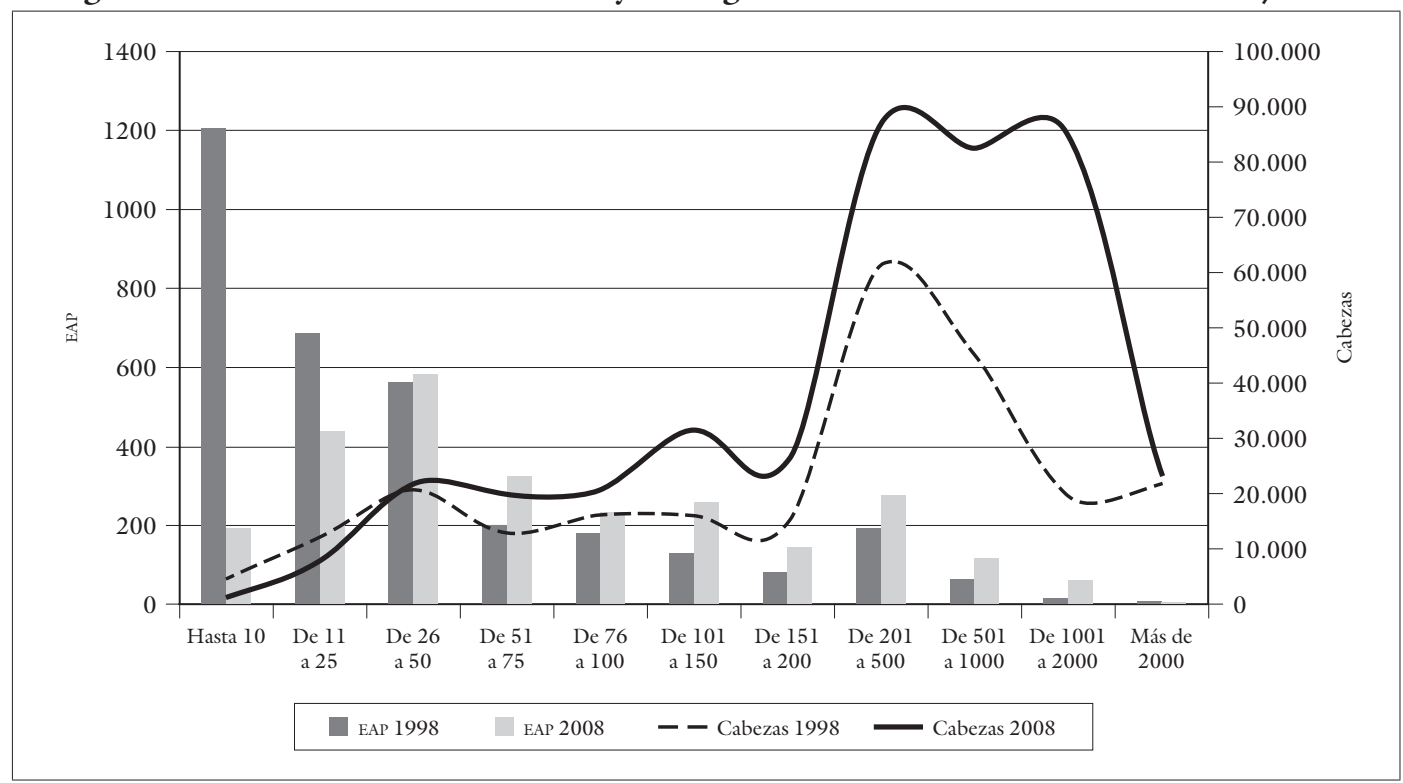

Fuente: Elaboración propia con base en datos CNA 1988 y 2008. Indec. 
Figura 4. Cantidad de EAP y existentes bovinas según tamaño del rodeo. Variación absoluta 1988-2008/ Departamentos ganaderos y Mendoza

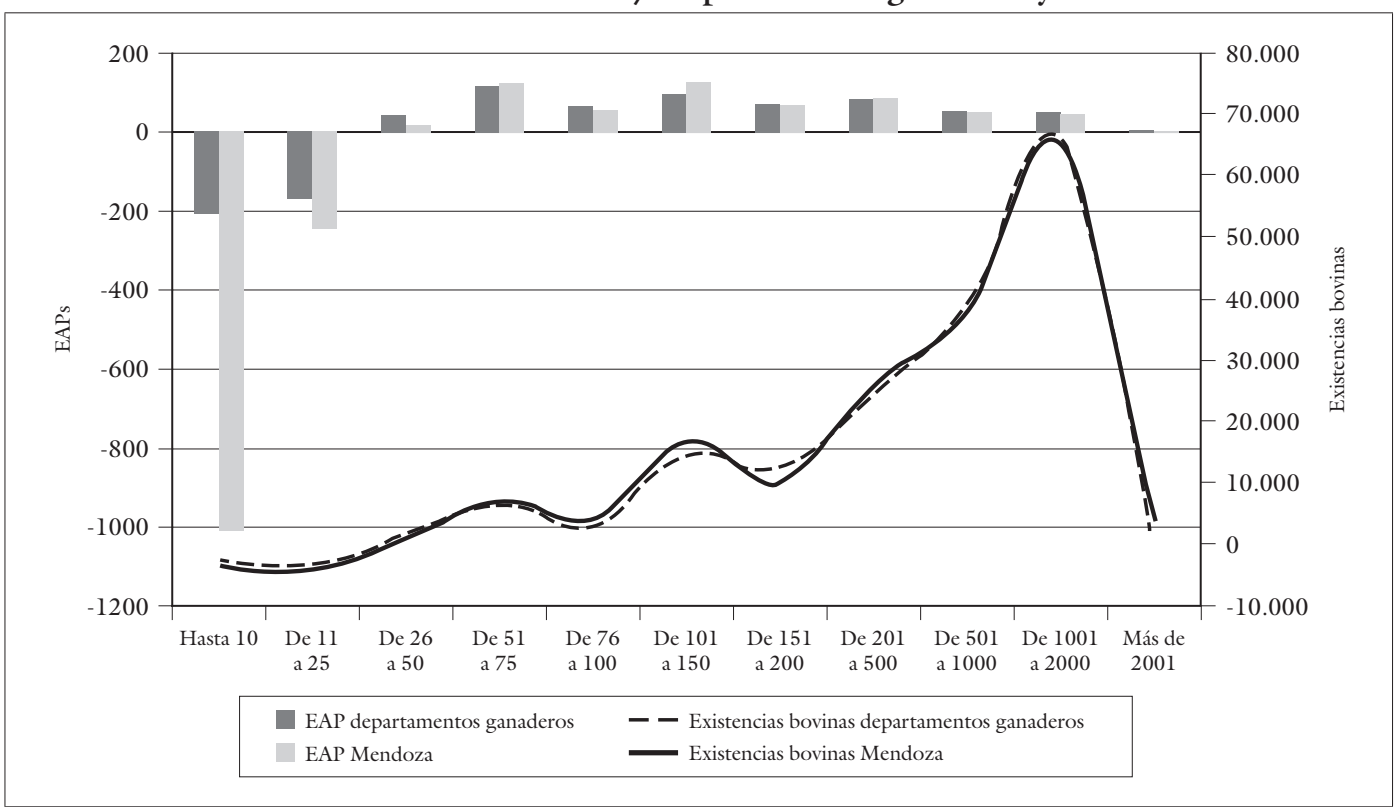

Fuente: Elaboración propia con base en datos CNA 1988 y 2008. Indec.

las explotaciones que se ubican por encima del rango de las 1000 cabezas.

Por su parte, mientras la caída de las explotaciones que controlan rodeos más pequeños se extienden en Mendoza más allá de los departamentos ganaderos, las que controlan rodeos mayores se concentran casi enteramente en estos (figura 5). La clasificación de pequeños productores pecuarios construida con base en niveles de capitalización (Obschatko, Foti y Román, 2007) permite establecer que las EAP que en los departamentos ganaderos muestran las disminuciones más abruptas (menos de 50 cabezas) se corresponden con el estrato 'inferior' de pequeños productores fami- liares 'inviables', es decir entre quienes la dotación de recursos no les permite vivir exclusivamente de su explotación y mantenerse en la actividad.

Además, los departamentos del sur (Malargüe, San Rafael y General Alvear), que expresan las mayores concentraciones de ganado bovino, poseen amplias superficies en condición de no irrigado y aun así ostentan, al interior de ecosistemas de tierras secas, mayores precipitaciones (Norte, 2000). En contraposición y como se verá luego, las existencias caprinas se concentran allí donde las precipitaciones se vuelven más exiguas y se hace necesario recurrir a especies ganaderas mejor adaptadas a con- 
Figura 5. Cantidad de EAP con existencias bovinas y cantidad de cabezas según tamaño del rodeo. Departamentos ganaderos de Mendoza, 2008

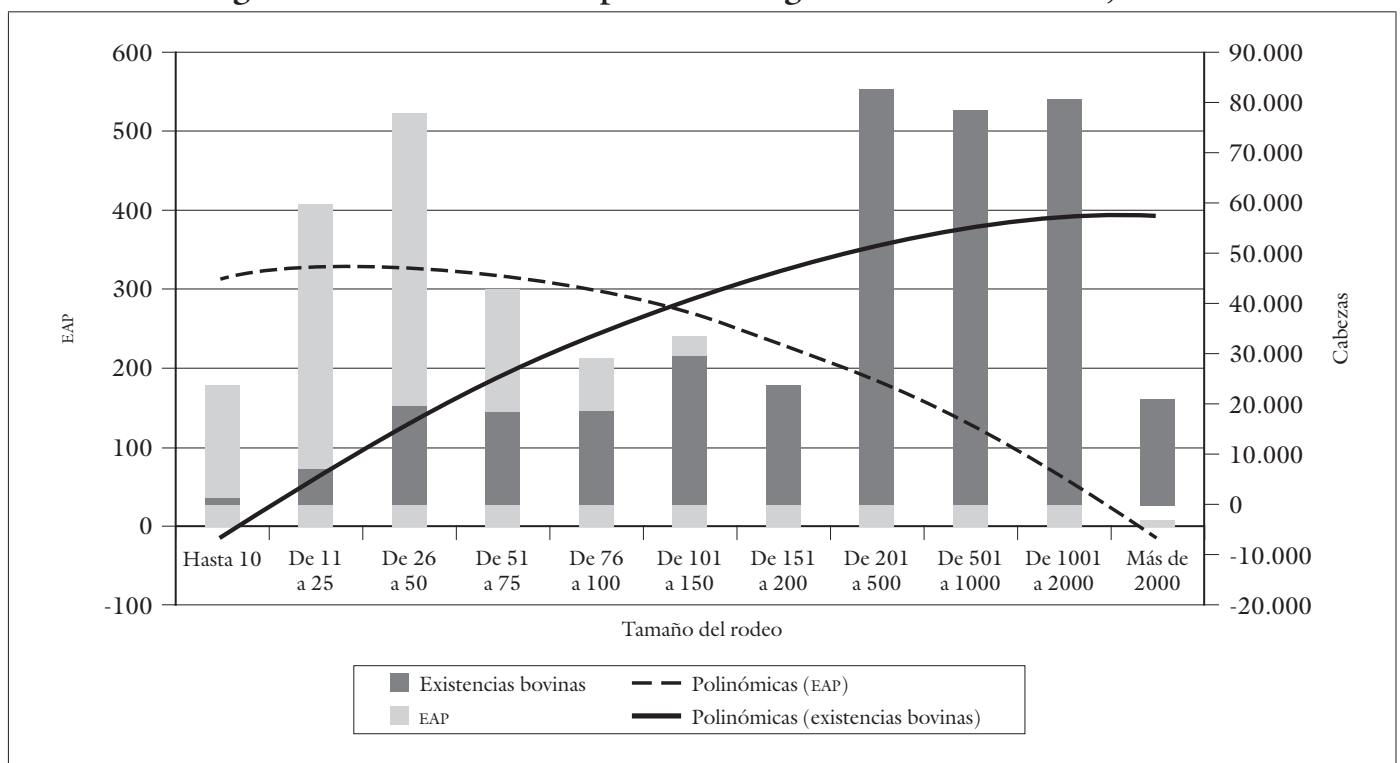

Fuente: Elaboración propia con base en datos CNA 2008. Indec.

diciones agroecológicas más restrictivas (Bedotti, 2008).

En relación a la ganadería caprina, los datos de 1988 y 2008 permiten observar un leve aumento del stock (6\%) y una disminución — también leve $(-2 \%)$ — en la cantidad de EAP. En este caso, los departamentos que exhiben las mayores concentraciones del stock son Malargüe (58\%), Lavalle (20\%) y San Rafael (13\%). Por su parte y esta vez a diferencia de lo que ocurre en el caso bovino, en la ganadería caprina, las explotaciones sin límites definidos superan ampliamente a sus pares con límites (tabla 4), con un $68 \%$ y $32 \%$, respectivamente.

La evolución histórica de la ganadería caprina resulta menos errática que la ga- nadería bovina, lo que evidencia un crecimiento más sostenido a lo largo de casi 120 años (figura 6). Cuando menos dos factores podrían estar coadyuvando para que Mendoza evidencie estas tendencias. Por un lado, el ganado caprino se ha resguardado históricamente en manos de explotaciones familiares sin límites definidos, preferentemente orientadas al autoconsumo, mientras sus pares bovinos —orientados en mayor proporción a los intercambios mercantiles - han resultado más sensibles a las fluctuaciones de mercado. Por otra parte, el constituir Mendoza un contexto de tierras secas - cuya constante ambiental está dada por la alta variabilidad en las lluvias - podría determinar que en períodos 
Tabla 4. Existencias ganaderas caprinas por departamento. Mendoza, 2008

\begin{tabular}{|c|c|c|c|c|}
\hline & Totales & $\begin{array}{l}\text { Explotaciones con } \\
\text { límites definidos }\end{array}$ & $\begin{array}{l}\text { Explotaciones sin } \\
\text { límites definidos }\end{array}$ & $\begin{array}{l}\text { Existencias caprinas por de- } \\
\text { partamento. En porcentajes }\end{array}$ \\
\hline Mendoza & 657788 & 207806 & 449982 & $100 \%$ \\
\hline Capital & - & - & - & - \\
\hline General Alvear & 7093 & 6623 & 470 & $1 \%$ \\
\hline Godoy Cruz & 362 & - & 362 & $0,05 \%$ \\
\hline Guaymallén & 25 & 25 & - & $0,003 \%$ \\
\hline Junín & 76 & 76 & - & $0,001 \%$ \\
\hline $\mathrm{LaPaz}$ & 8026 & 8026 & - & $1,2 \%$ \\
\hline Las Heras & 5786 & 485 & 5301 & $0,9 \%$ \\
\hline Lavalle & 134155 & 15069 & 119086 & $20 \%$ \\
\hline Luján de Cuyo & 4513 & 926 & 3587 & $0,7 \%$ \\
\hline Maipú & 1826 & 1826 & - & $0,3 \%$ \\
\hline Malargüe & 380827 & 122046 & 258781 & $58 \%$ \\
\hline Rivadavia & 153 & 153 & - & $0,2 \%$ \\
\hline San Carlos & 15841 & 12737 & 3104 & $2,4 \%$ \\
\hline San Martín & 1822 & 1822 & - & $0,3 \%$ \\
\hline San Rafael & 85943 & 29191 & 56752 & $13 \%$ \\
\hline Santa Rosa & 8316 & 6751 & 1565 & $1,3 \%$ \\
\hline Tunuyán & 625 & 625 & - & $0,09 \%$ \\
\hline Tupungato & 2399 & 1425 & 974 & $0,4 \%$ \\
\hline
\end{tabular}

Fuente: Elaboración propia con base en datos del Censo Nacional Agropecuario 2008. Indec.

de sequía se vean más afectadas las especies ganaderas menos adaptadas a condiciones extremas (ganado bovino, entre otras).

Más cerca en el tiempo, los datos censales 2002-2008 permiten advertir que también en el seno de las explotaciones caprinas, las sin límites definidos caen un $17 \%$ y las que poseen límites definidos, aumentan un $11 \%$. Complementariamente, mientras las primeras perdieron el $18 \%$ del stock, las segundas registran un aumento del $41 \%$.

Autores que han analizado tópicos similares en zonas de características análogas a las que exhibe Mendoza indican que las 
Figura 6. Existencias bovinas y caprinas. Mendoza 1895-2008

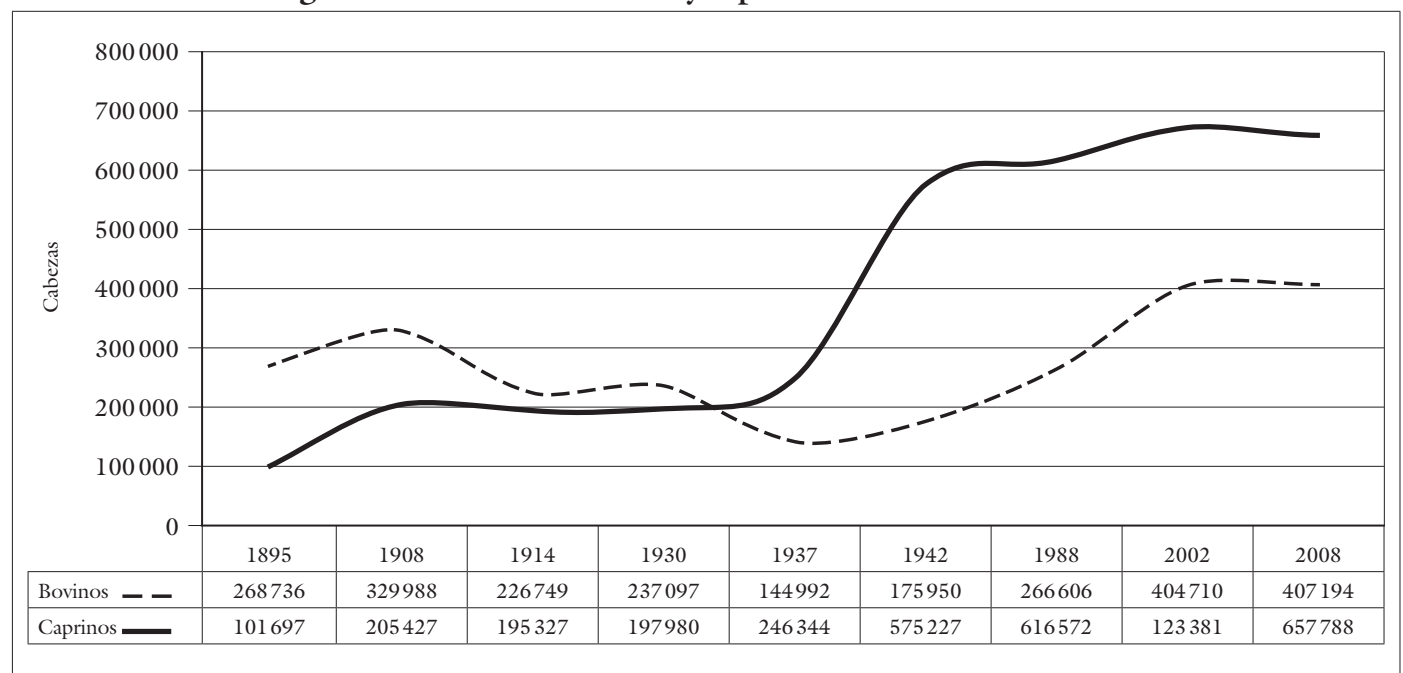

Fuente: Elaboración propia con base en datos censales 1895, 1908, 1914, 1930, 1937, 1942, 1988, 2002 y 2008. Indec.

nuevas condiciones de expansión del capitalismo supone un franco proceso de avance de la propiedad privada y de cercamientos por la introducción de alambrados; forma de uso y aprovechamiento de los recursos naturales que difiere de las estrategias de uso común del territorio características del campesinado extrapampeano argentino. En esta línea, Cáceres (2009) advierte que los pequeños productores, antes orientados a la cría extensiva de ganado caprino y que hacían uso de grandes superficies, ven restringidos sus campos de pastoreo por la subrepticia introducción de alambrados en los campos vecinos de perfil capitalista y como consecuencia, ven extinguirse sus majadas caprinas.

En correspondencia con estas observaciones, los datos disponibles para Mendoza permiten advertir, además de la caída de las explotaciones sin límites definidos, una importante disminución de las más pequeñas con límites definidos (figura 7).

El gráfico anterior muestra dos ejes de análisis para Mendoza y para los departamentos ganaderos profundamente relacionados: en barras, la cantidad de explotaciones agropecuarias con existencias de ganado caprino para 2008 y, en líneas, la variación en el número de EAP con ganado caprino (1988-2008). Tomando como punto de referencia las EAP existentes en 2008 es posible advertir que las mayores disminuciones se producen entre las unidades más pequeñas (rodeos de hasta 100 cabezas), mientras los mayores aumentos se concentran en las explotaciones que controlan rodeos de entre 101 y 500 cabezas.

Por su parte, el Senasa informa que en 2013, los establecimientos caprinos más 
5 Aqui las tecnologías se entenderán a partir de la clasificación entre tecnologias de insumos y de proceso, propuesta por Viglizzo. Las primeras, son de carácter tangible, refieren a lo material y poseen un costo económico. Dentro de estas se encontraria la maquinaria agropecuaria, vacunas, semillas mejoradas, etc. Las segundas, en cambio, se caracterizan por ser inmateriales y por involucrar un componente de información, conocimiento y eficiencia. Poseen costo intelectual más que económico y su aplicación resulta de mayor dificultad que las anteriores. Ejemplo de estas últimasson las tecnologías de manejo y la gestión (Viglizzo, 1994).

${ }^{6}$ De acuerdo con el Indec, dentro de este grupo se reunen las actividades ganaderas caracteristicas de las zonas áridas y semiáridas del pais, en su gran mayoría extensivas, que implican un escaso manejo del rodeo y que, en general, tienen lugar en el seno de explotaciones sin apotreramiento.

\section{tersitarias 30}

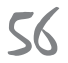

Figura 7. Cantidad de EAP con existencias caprinas según tamaño del rodeo 2008 y variación absoluta 1988-2008. Mendoza y departamentos ganaderos

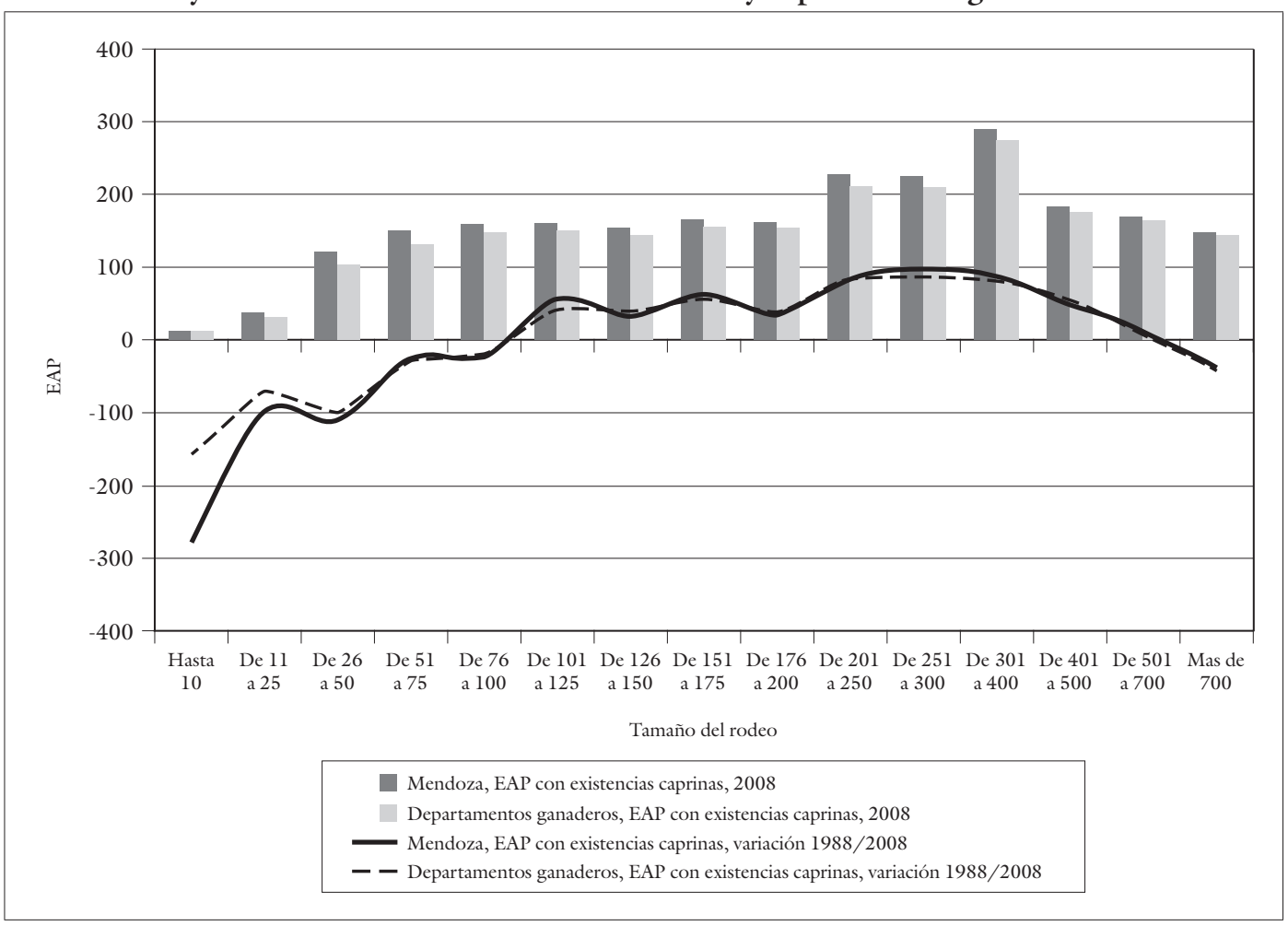

Fuente: Elaboración propia con base con datos CNA 1988, 2008. Indec.

pequeños (hasta 250 cabezas) representaban el $66 \%$ del total y controlaban el $10 \%$ de las existencias caprinas provinciales, los ubicados en el rango intermedio (entre 250 y 1000$)$ representaban el $27 \%$ del total y controlaban el $24 \%$ de las existencias y, finalmente, los establecimientos de mayores dimensiones (más de 1000) representaban el $7 \%$ del total y controlaban el $66 \%$ de las existencias caprinas provinciales (Senasa, 2013) (figura 8).
Los datos analizados que permiten sustentar la existencia de tendencias a favor de la concentración de la producción en Mendoza se complementan con otros referidos a los tipos de rodeo y prácticas de manejo, que resultan indicativos de una disposición a la incorporación de tecnología,${ }^{5}$ especialmente en relación a la producción bovina.

En términos generales, entre 20022008 la provincia muestra leves aumentos, tanto de la ganadería no especializada ${ }^{6}$ 
Figura 8. Distribución de los establecimientos con existencias caprinas según estrato. Mendoza 2013

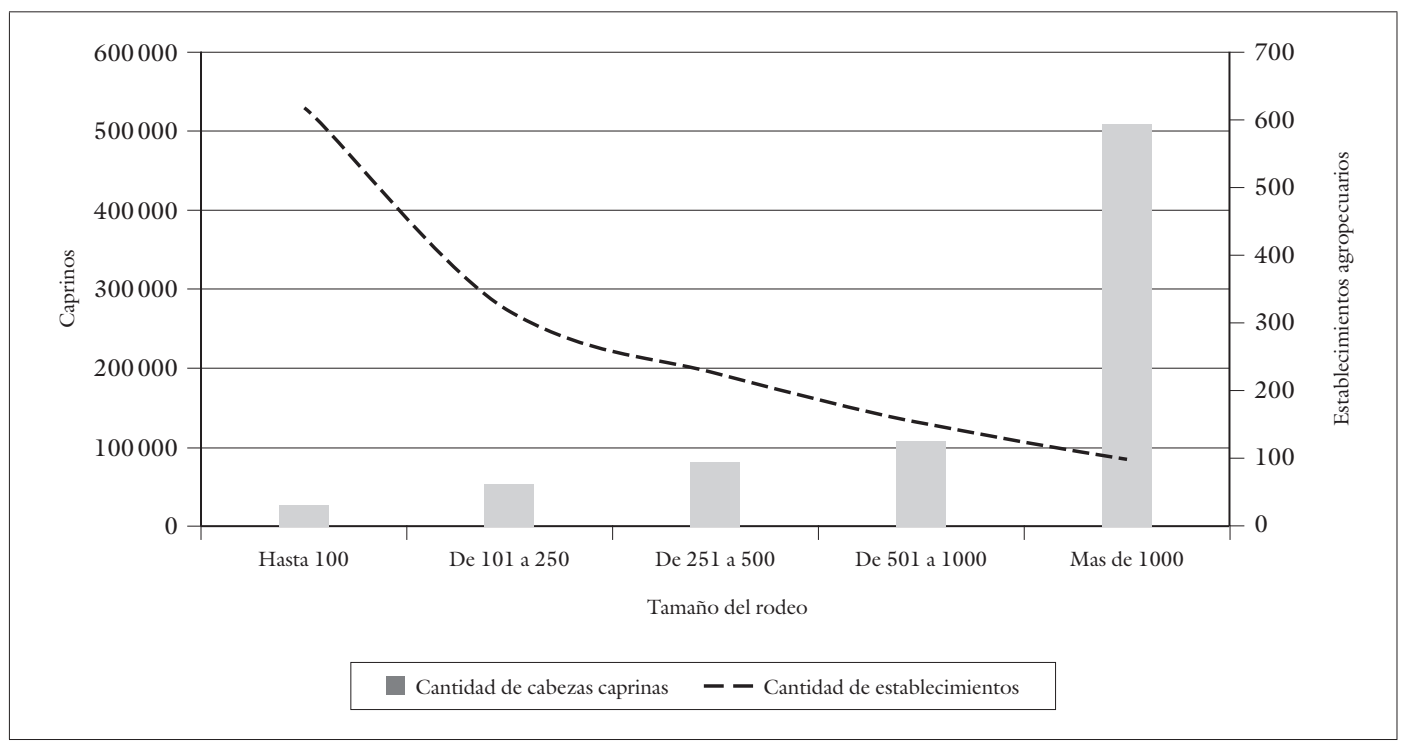

Fuente: Elaboración propia con base en datos Senasa, 2013.

(10\%) como de la ganadería especializada ${ }^{7}$ (4\%), que pueden resultar atribuibles al incremento general del stock bovino provincial (tabla 3 ). Por su parte, dentro de la ganadería especializada, las actividades de cría decrecen un $14 \%$ y las de recría aumentan el $160 \%$ (tabla 5).

El análisis pormenorizado de los departamentos ganaderos de Mendoza permite realizar algunas consideraciones complementarias, en especial relación a los procesos de cambio que se constatan al interior de la ganadería especializada. En este sentido, se observa que sobre una tendencia provincial de decrecimiento de las actividades de cría, cinco de los siete departamentos ganaderos de Mendoza acusan tendencias inversas. Es el caso de Lavalle que registra un incremento del $1089 \%$, Malargüe (240\%), Santa Rosa (207\%), La Paz $(47 \%)$ y San Carlos (18\%). Entre los departamentos ganaderos solo dos, San Rafael y General Alvear, acusan tendencias decrecientes (-39 y $-34 \%$, respectivamente).

Ahora bien, se observa al mismo tiempo que son justamente los departamentos que disminuyen la cantidad de cabezas en cría, los que aumentan las existencias en recría (General Alvear con un 608\% y San Rafael con un $123 \%$, además de San Carlos con un $80 \%$ ).

Estos datos podrían estar indicando cierta disposición a favor de la especialización territorial de la producción, con departamentos preferentemente orientados a la producción de terneras y terneros para
${ }^{7}$ La ganadería especializada, en cambio, implica un mayor manejo del rodeo $y$ permite la clasificación interna de la actividad en cría, recría, invernada (engorde), tambo, cabaña y otros. 
${ }^{8}$ Las prácticas de manejo que el censo revela se acomodan a la definición que aporta Carrillo (1988) para quien constituyen "el arte y la ciencia de conocer, planificar y dirigir el uso de los recursos con que se cuenta, a fin de optimizar la producción, manteniéndola o incrementándola a través del tiempo sin afectar los recursos naturales" (p. 28). Quedan por tanto excluidas otras prácticas de manejo especialmente implementadas por los pequeños productores y que suelen ser despectivamente tildadas de rudimentarias e irracionales por no emanar del saber científico-tecnológico (Barkin et al, 2009).

${ }^{9}$ Para el CNA 1988, la fuente de información refiere a la cantidad de EAP dedicadas a cría e invernada (de manera exclusiva o combinada) que desarrollan prácticas de manejo (estacionamiento de servicio, diagnóstico de preñez e inseminación artificial, invernada sin suplementación y con suplementación alimentaria). $\Upsilon$ para los años 2002 y 2008, el CNA releva EAP con limites definidos con rodeos bovinos de carne, por tamaño del rodeo, que realizan prácticas de manejo (servicio natural a corral, estacionamiento de servicio, diagnóstico de preñez, inseminación artificial y trazabilidad).

\section{territarias 30}

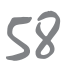

Tabla 5. Cantidad de existencias bovinas en EAP con límites definidos por tipo de rodeo. Departamentos ganaderos de Mendoza. Variación relativa 2002-2008

\begin{tabular}{|l|r|r|r|r|r|r|r|r|r|}
\hline \multicolumn{2}{|c}{ Ganadería no especializada } & \multicolumn{6}{c|}{ Gría } & \multicolumn{3}{c|}{ Recría } \\
\cline { 5 - 11 } & 2002 & 2008 & $\begin{array}{c}\text { Variación } \\
\text { relativa }\end{array}$ & 2002 & 2008 & $\begin{array}{c}\text { Variación } \\
\text { relativa }\end{array}$ & 2002 & 2008 & $\begin{array}{c}\text { Variación } \\
\text { relativa }\end{array}$ \\
\hline Mendoza & 89469 & 97166 & $10 \%$ & 190298 & 164510 & $-14 \%$ & 13334 & 34679 & $160 \%$ \\
\hline General Alvear & 6698 & 1970 & $-71 \%$ & 62083 & 41216 & $-34 \%$ & 2500 & 17568 & $603 \%$ \\
\hline La Paz & 23316 & 7834 & $-66 \%$ & 14765 & 21785 & $47 \%$ & 1909 & 463 & $-76 \%$ \\
\hline Lavalle & 2228 & 2376 & $7 \%$ & 147 & 1748 & $1089 \%$ & 137 & 22 & $-84 \%$ \\
\hline Malargüe & 19834 & 35697 & $80 \%$ & 747 & 2544 & $241 \%$ & 430 & 105 & $-76 \%$ \\
\hline San Carlos & 582 & 5647 & $870 \%$ & 23153 & 27276 & $18 \%$ & 1108 & 1979 & $79 \%$ \\
\hline San Rafael & 20175 & 32318 & $60 \%$ & 76105 & 46316 & $-39 \%$ & 5745 & 12833 & $123 \%$ \\
\hline Santa Rosa & 12358 & 4185 & $-66 \%$ & 5622 & 17237 & $207 \%$ & 1180 & 956 & $-19 \%$ \\
\hline
\end{tabular}

* Dado que representan exiguos valores, se excluyen las actividades de invernada, tambo, cabaña y otros.

Fuente: Elaboración propia con base en datos del CNA 2002-2008. Indec.

la venta (Lavalle, Malargüe y Santa Rosa) y otros a incrementar el peso de los terneros recientemente destetados para su posterior traslado a la invernada y terminación (General Alvear, San Carlos y San Rafael).

Aun cuando especialistas en la temática se resisten a asociar de manera a-problemática recría-modernización por cuanto Mendoza exhibe condiciones ambientales que pueden tornar riesgoso avanzar en la cadena de producción más allá de la cría, no resulta un dato menor que los departamentos que acusan un incremento en las actividades de recría ostenten mayores precipitaciones a la magra media provincial ( $200 \mathrm{~mm} /$ año) y que las actividades de cría se vuelquen allí donde estas disminuyen y las incertidumbres aumentan.
Si bien el CNA 1988 releva las prácticas de manejo ${ }^{8}$ según categorías que difieren de las que se utilizan en forma posterior

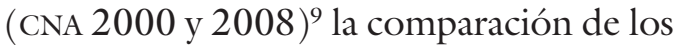
datos disponibles permite advertir un importante incremento en la cantidad de EAP que desarrollan algún tipo de práctica de manejo, incluso al interior de un proceso más general caracterizado por el descenso en el número total de EAP (tabla 6).

Mientras en 1988 de un total de 2102 explotaciones el $14 \%$ realizaba prácticas de manejo, en 2002 la proporción aumenta al $44 \%$ y en 2008 a $58 \%$, evidenciándose un incremento acumulado del $186 \%$ a lo largo de 20 años.

La desagregación de las prácticas de manejo en los distintos tipos que los cen- 
sos consideran permite observar, por su parte, que entre 2002 y 2008 , todas ellas acreditan incrementos (tabla 7), particularmente evidentes en las prácticas de trazabilidad.

El aumento del $65 \%$ en la implementación de prácticas de manejo en las explotaciones con rodeos de distintos tamaños (a excepción de aquellas que poseen más de 2000 existencias donde disminuyen un $42 \%$ ) (tabla 7 y figura 9) indica una propensión a la especialización de la producción, progresivamente gobernada por las reglas de la economía de mercado. Esto se ve reflejado en el incremento del $436 \%$ de EAP que desarrollan prácticas de trazabilidad. Se trata de un seguimiento certificado, orientado a ubicar productos en mercados externos cada vez más exigentes, que consta de una importante tarea de logística y controles de calidad exhaustivos. Según Aráoz "los sistemas de trazabilidad disponibles en la Argentina tienen un costo muy variable, de acuerdo a las características de los mismos, que oscila entre 2 y 10 kilos de carne por cabeza" (2004, p. 26).

En efecto, la aplicación de cualquiera de las prácticas de manejo relevadas, no solo la trazabilidad, eleva los costos de operación; implica la realización de inversiones económicas aunque no con igual intensidad y en los mismos factores de producción (capacitación, servicios técnicos, equipamiento, insumos, horas de trabajo, entre otros).

Tabla 6. Cantidad de EAP con rodeos de carne bovina que realizan prácticas de manejo. Variación relativa 1988-2008. Mendoza

\begin{tabular}{|l|c|c|c|c|}
\hline & 1988 & 2002 & 2008 & $\begin{array}{c}\text { Variación relativa } \\
(\mathbf{1 9 8 8}-2008)\end{array}$ \\
\hline EAP totales en rodeos de carne & 2102 & 1422 & 1417 & $-32 \%$ \\
\hline EAP que realizan prácticas de manejo & 288 & 628 & 825 & $186 \%$ \\
\hline
\end{tabular}

Fuente: Elaboración propia con base en datos del CNA 1988-2008, DEIE.

Tabla 7. Cantidad de EAP con límites definidos y rodeos de carne bovino, por práctica de manejo. Variación relativa 2002-2008. Mendoza

\begin{tabular}{|c|c|c|c|}
\hline & 2002 & 2008 & Variación relativa \\
\hline Servicio natural a corral & 410 & 627 & $53 \%$ \\
\hline Diagnóstico de preñez (palpación) & 128 & 214 & $67 \%$ \\
\hline Trazabilidad & 25 & 134 & $436 \%$ \\
\hline Total & 743 & 1225 & $65 \%$ \\
\hline
\end{tabular}

Fuente: Elaboración propia con base en datos del CNA 2002-2008, DEIE. 
Figura 9. Cantidad de EAP con límites definidos con rodeos de carne bovina, que realizan prácticas de manejo, según tamaño de rodeo. Mendoza 2002, 2008

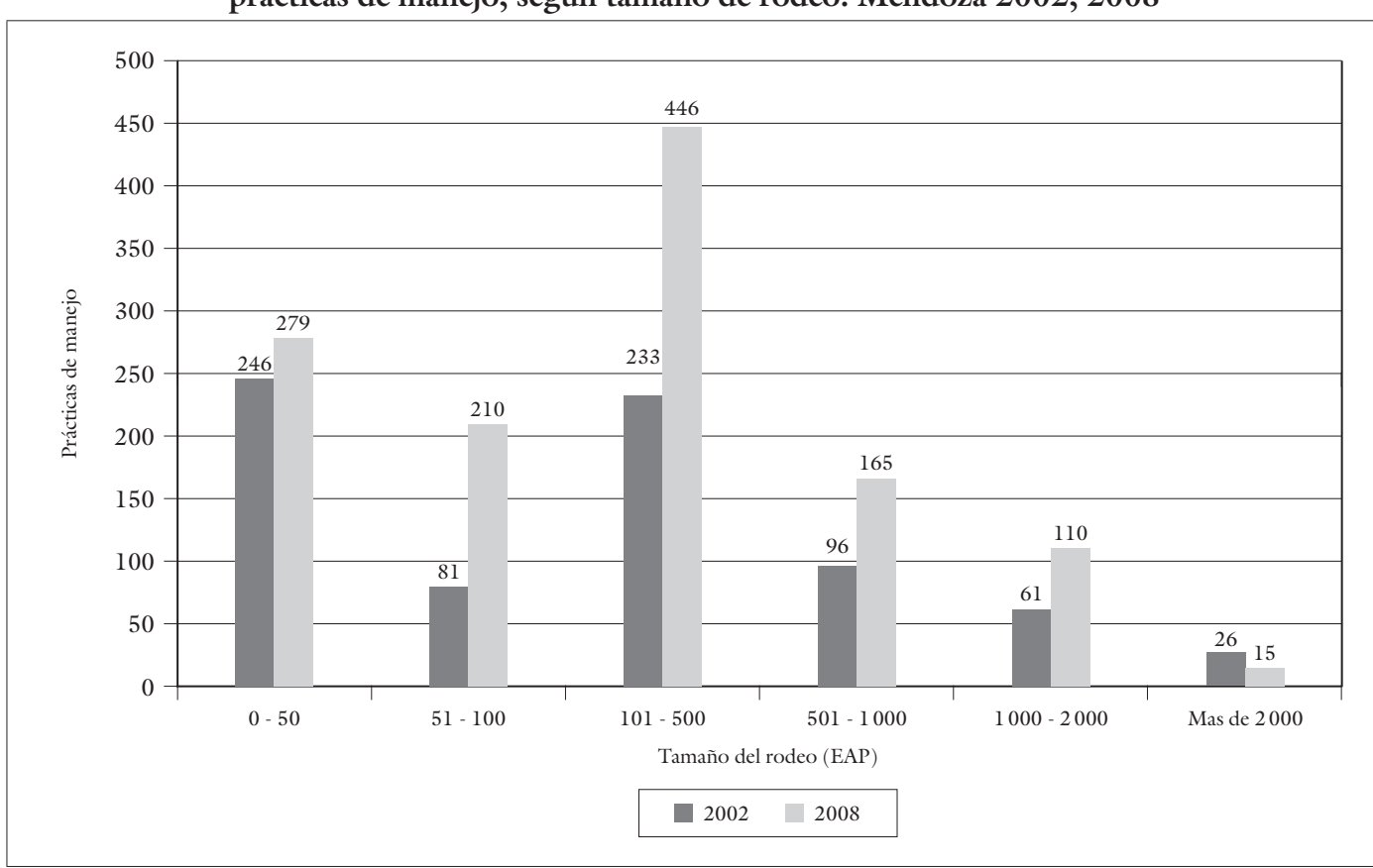

Fuente: Elaboración propia con base en datos CNA 2002-2008. Indec.

Por lo tanto, guiándonos por los datos de la figura 9, es posible interpretar que las EAP con rodeos de menor tamaño (de 1 a 500 cabezas), aquellas dirigidas por pequeños productores (Obschatko et al, 2007), han debido capitalizarse, incorporando tecnologías a los efectos de intensificar la producción y ajustar la relación costo-beneficio para persistir en la actividad. Si bien el aumento de las prácticas de manejo en EAP con rodeos de hasta 50 cabezas no es cuantioso $(13 \%)$, sí lo es para aquellas EAP que poseen entre 51 y 100 cabezas (159\%) y entre 101 y 500 cabezas (91\%).
En resumidas cuentas y aun admitiendo que se trata de datos que se deben considerar con cautela hasta tanto se puedan enriquecer y ajustar con otros de mayor nivel de desagregación, se observan tendencias a la especialización e incorporación de tecnologías.

Por último y respecto de la extranjerización de tierras, el Ministerio de Justicia y Derechos Humanos de Argentina informa que la provincia de Mendoza se ubica en séptimo lugar a nivel nacional en atención a la cantidad de tierras rurales en manos de extranjeros (mapa 2). 
Mapa 2. Hectáreas en manos de extranjeros. Provincia de Mendoza, año 2013

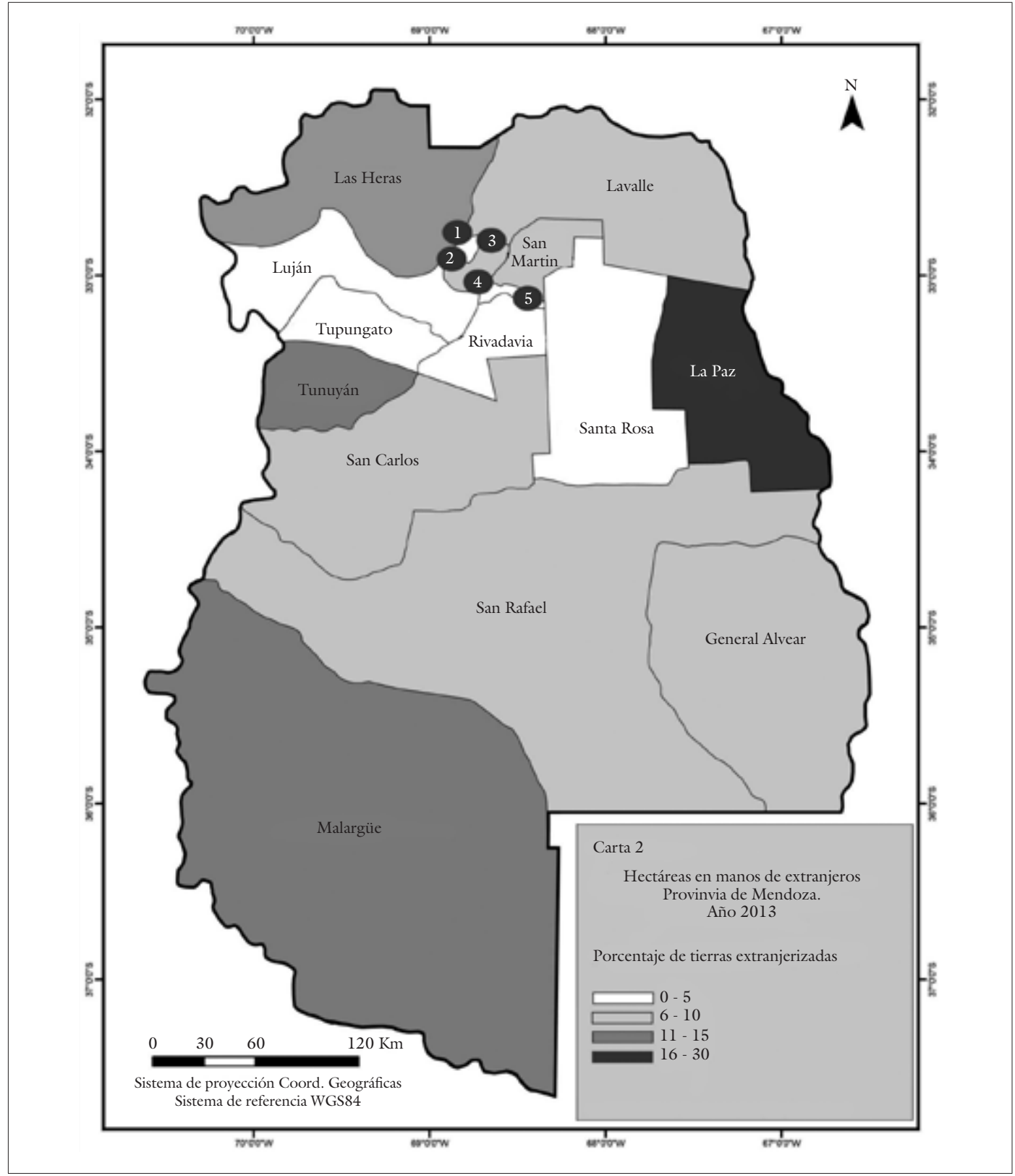

Fuente: Elaboración propia. 
Según se desprende del análisis de la carta anterior, entre los departamentos que ostentan las mayores presencias se encuentran La Paz y Malargüe, dos de aquellos que acusan las mayores curvas de crecimiento en materia ganadera en los últimos años. Lamentablemente, la información a la que se ha tenido acceso no permite conocer las actividades productivas a las que se orientan estas tierras; tampoco saber si se hallan en producción. Paralelamente, por la manera como se han construido los datos, estos se deben considerar con cautela, como 'datos de mínima' y sujetos a continua renovación, pero al mismo tiempo como indicativos de tendencias, probablemente inacabadas pero en curso, que estarían señalando una alta presencia de capitales extranjeros en Mendoza, incluso por fuera de los territorios-bastión de la nueva vitivinicultura.

En definitiva, en Mendoza los territorios del sur y este provincial no solo han visto aumentadas sus existencias ganaderas totales, acusan tendencias a la concentración de la producción y a la desaparición de las unidades más pequeñas y sin límites definidos, sino además presentan tendencias a la especialización de las actividades ganaderas, a la incorporación de tecnologías y una fuerte presencia de propietarios extranjeros.

\section{Consideraciones finales}

En el presente trabajo hemos intentado reflexionar sobre los procesos de avance de la lógica del capital en espacios locales de la provincia de Mendoza, en virtud de una revisión de los desbalances en el conocimiento teórico. En este sentido, se ha identificado que a nivel nacional los estudios se centran en indagar los aspectos netamente económicos o ambientales y sociales de los procesos de agriculturización ligados a la producción de soja transgénica, quedando parcialmente relegados los cambios acaecidos en otros sectores económicos tal como el caso del corrimiento e intensificación de la actividad ganadera capitalista. Para Mendoza, si bien la ganadería constituye una actividad económico-productiva de importancia, no se ha constituido en objeto de estudio académico en función de los procesos de reconversión productiva que se intensificaron a partir de 1990. Esta última ha sido pensada particularmente y con intensidad para la agroindustria vitivinícola, actividad emblemática de la provincia.

En virtud de los cruces de datos realizados de manera sincrónica y diacrónica, es posible sostener que la ganadería bovina capitalista ha avanzado en la geografía mendocina. Si bien los antecedentes teóricos y las fuentes estadísticas indican la existencia de condiciones agroecológicas que limitan la expansión de la cadena de producción de carnes en la provincia, el sector - o por lo menos la producción bovina - han surcado en los 20 años analizados procesos de concentración de la producción e incorporación de tecnologías. Estas tendencias se ven reflejadas en la reducción de la cantidad de EAP ganaderas - en particular aquellas de rodeos pequeños y sin límites definidosen contraste con el aumento del stock; en 
la marcada tendencia a la especialización productiva y en la incorporación de prácticas de manejo tales como la trazabilidad.

Los departamentos sureños de San Rafael y General Alvear se encuentran entre los que disponen de mayor cantidad de existencias bovinas lo que coincide, no casualmente, con mayores precipitaciones y con el crecimiento de las actividades de recría.

Se observa también, que las EAP que se reducen más acusiadamente son las que se encuentran en manos de pequeños productores, que, según la clasificación de Obtchatko, Foti y Román (2007) presentan dificultades para insertarse en los mecanismos de mercado, de lo que se desprende, a su vez, que aquellas explotaciones pequeñas que han subsistido son las que lograron incorporar tecnologías. En efecto, los cambios acaecidos en las últimas dos décadas en el sector, profundizaron las desigualdades sociales y han generado la desaparición de aquellos que no computan como agentes competitivos en el sistema económico vigente.

Por otro lado, la reducción notable de las EAP sin límites definidos estaría indicando, además, procesos de mercantilización de los recursos naturales que antes se regian como bienes comunes.

Asimismo son relevantes los datos disponibles acerca del acrecentamiento de tierras en manos de actores extranjeros, tierras que durante largo tiempo no constituyeron un polo de interés para inversionistas.

Así las cosas y aun admitiendo que los procesos de avance del capitalismo dialogan de manera constante con las particularidades que exhiben los territorios locales, los datos analizados estarían indicando que Mendoza surca en el presente procesos análogos a los que tienen lugar en otros territorios extrapampeanos del país, sujetos a una fuerte avanzada (re)territorializadora del capital.

Finalmente, el trabajo ilustra una vez más, la importancia de contar con información estadística actualizada, de mayor profundidad y de calidad, que habilite lecturas particularizadas de la diversidad que contiene el sector agropecuario en los niveles regionales.

\section{Referencias}

Aizen, M. A., Garibaldi, L. A y Dondo, M. (2009). Expansión de la soja y diversidad de la agricultura argentina. Ecología Austral, (19), 45-54.

Albuquerque, F. (1999). Desarrollo económico local en Europa y América Latina. Madrid: Consejo Superior de Investigaciones Científicas.

Agencia Provincial de Ordenamiento Territorial (АРОТ). (2013). Sensible aumento en la superficie de los oasis de Mendo$z a$. Recuperado de http://www.ambiente.mendoza.gov.ar/index.php/ boletin/339-sensible-aumento-en-lasuperficie-de-los-oasis-de-mendoza

Aráoz, L. (2004). Trazabilidad de la carne bovina en la Argentina. Documento de perfil detallado de proyecto. Buenos Aires: FAO. territarias 30 
Azcuy, E. y Ortega, L. (2009). Expansión de la frontera agropecuaria, reestructuración ganadera y sojización en regiones extrapampeanas. Ponencia presentada en XV Jornadas de Epistemología de las Ciencias Económicas. Universidad de Buenos Aires, Buenos Aires.

Bedotti, F. (octubre, 2008). El rol social del ganado caprino. Ponencia presentada en Congreso Argentino de Producción Animal, San Luís, Argentina.

Cáceres, D. Silvietti, F., Ferrer, G, Sotto, G. y Bisio, C. (2009). Agriculturización y Estrategias campesinas en el norte de la provincia de Córdoba. En Actas de las VI Jornadas Interdisciplinarias de Estudios Agrarios y Agroindustriales. Buenos Aires: Universidad de Buenos Aires.

Carrillo, J. (1988). Manejo de un rodeo de cría. Buenos Aires: Centro Regional Buenos Aires Sur.

Charvay, P. (2012). Los cambios en la producción ganadera en la posconvertibilidad. La expansión sojera y su impacto sobre la ganadería las nuevas formas de producción. Voces en el Fénix, 3(12), 22-29.

Comerci, M. E. (2010). Tenemos que ir allá y pegar la vuelta. Continuidades y cambios en las prácticas de movilidad campesinas en contextos de conflictividad emergente. Revista Transporte y Territorio, (3), 77-102.

Domínguez, M. (2003). Los procesos de resistencia al conflicto armado y al desplazamiento forzado por parte de pobladores rurales afrocolombianos en el municipio de Buenaventura. Buenos Aires: Consejo Latinoamericano de Ciencias Sociales. Domínguez, N. A y Orsini, G. (2009). Impactos en la estructura agraria por la ampliación de la frontera agricola en base a la expansión del cultivo de soja en la región pampeana: la historia reciente de Entre Rios. 1. ${ }^{a}$ ed. Buenos Aires: Ediciones Cooperativas.

Domínguez, S. y Sabatino, P. (2006). Con la soja al cuello: crónica de un país hambriento productor de divisas. En: $\mathrm{H}$. Alimonda, Los tormentos de la materia. Aportes para una ecología politica latinoamericana (pp. 249-274). Buenos Aires: Consejo Latinoamericano de Ciencias Sociales.

Fanjul, J. A. (2012). Competitividad de la cria de ganado vacuno en Mendoza: destete precoz - factores criticos (Tesis de grado, Universidad Nacional de Cuyo, Mendoza, Argentina). Recuperado de http://bdigital.uncu.edu.ar/4595

Galafassi, G. (2012). Entre viejos y nuevos cercamientos. La acumulación originaria y las políticas de extracción de recursos y ocupación del territorio. Revista Theomai, (826, segundo semestre), s. p.

González, M. y Román, M. (2009). Expansión agrícola en áreas extrapampeanas de la Argentina. Una mirada desde los actores sociales. Cuadernos de Desarrollo Rural, 6(61), 99-120.

Gras, C. (2005). Entendiendo el agro: trayectorias sociales y reestructuración productiva en el noroeste argentino. Buenos Aires: Biblos.

\section{tersitarias 30}


Gras, C. y Hernández, V. (2009). La Argentina rural. De la agricultura familiar a los agronegocios. Buenos Aires: Editorial Biblos.

Grünwaldt, E. y Guevara, J. C. (2011). Rentabilidad del engorde a corral de bovinos de carne en la provincia de Mendoza, Argentina. Mendoza: Universidad Nacional de Cuyo, Facultad de Ciencias Agrarias.

Gudynas, E. (2012). Estado compensador y nuevos extractivismos. Las ambivalencias del progresismo sudamericano. Nueva Sociedad, (237, enero-febrero), 128-146.

Hocsman, L. D. y Preda, G. (noviembre, 2005). Agriculturización y bovinización, la renovada territorialización capitalista en Córdoba (Argentina). Ponencia presentada en IV Jornadas Interdisciplinarias de Estudios Agrarios y Agroindustriales. Universidad de Buenos Aires, Buenos Aires, Argentina.

Instituto Nacional de Estadística y Censos (Indec) (1988). Censo Nacional Agropecuario. Recuperado de http://www. indec.mecon.ar/principal.asp?id_te$\mathrm{ma}=494$

Instituto Nacional de Estadística y Censos (Indec) (2002). Censo Nacional Agropecuario. Recuperado de http://www. indec.mecon.ar/principal.asp?id_te$\mathrm{ma}=494$

Instituto Nacional de Estadísticas y Censos. (2008). Censo Nacional Agropecuario. Mendoza: Indec.

Katz, J. y Kosacoff, B. (1989). El proceso de industrialización en Argentina: evo- lución, retroceso y prospectiva. Buenos. Aires: Cepal.

Kay, C. (mayo-junio, 1995). El desarrollo excluyente y desigual en la América Latina rural. Revista Nueva Sociedad, (137), 60-81.

Manuel-Navarrete D., Gallopín, G., Blanco, M., Díaz-Zorita, M., Ferraro, D., Herzer, H, Celis, A., et al. (2005). Análisis sistémico de la agriculturización en la pampa húmeda argentina y sus consecuencias en regiones extrapampeanas: sostenibilidad, brechas de conocimiento e integración de políticas. Naciones Unidas, Serie Medioambiente y Desarrollo 118. Santiago de Chile: Cepal

Manzanal, M. (2006). Regiones, territorios e institucionalidad del desarrollo rural. En: M. Manzanal, G. Neiman y M. Lattuada (comp.). Desarrollo rural. Organizaciones, instituciones y territorio (pp. 21-50). Buenos Aires: Ciccus.

Martinez-Alier, J. (2004). Los conflictos ecológico-distributivos y los indicadores de sustentabilidad. Revista Iberoamericana de Economía Ecológica, 1, 21-30.

McMichael, P. y Myhre, D. (1991). Global regulation vs the nation state: agro-food systems and the new politics of capital. Capital o class, 43(2), 83-106.

Milano, R. (septiembre, 2011). El nuevo escenario de la ganadería en Argentina. Revista de la Bolsa de Comercio de Rosario, $C(1514), 24-30$.

Norte, F. (2000). Provincia de Mendoza, Mapa de Clima. En E. M. Abraham y F. Rodríguez (ed.). Argentina. Recur- 
sos y Problemas Ambientales de la Zona Árida, Primera Parte: Provincias de Mendoza, San Juan y La Rioja, Tomo II. Mendoza: Iadiza, SDSyPA.

Obschatko, E., Foti, M. y Román, M. (2007). Los pequeños productores en la República Argentina: importancia en la producción agropecuaria y en el empleo en base al censo nacional agropecuario 2002, $2{ }^{2}{ }^{2}$ edición. Buenos Aires: Secretaría Agricultura, Ganadería, Pesca y Alimentos.

Observatorio Ganadero (2013). Caracterización regional: Pampeana. Observatorio de la Cadena de la Carne Bovina de Argentina, Informe 5. Buenos Aires: Badie.

Observatorio Ganadero (2013). Caracterización regional: Noreste argentino. Observatorio de la Cadena de la Carne Bovina de Argentina, Informe 4. Buenos Aires: Badie.

Paz, R. (octubre, 2011). Agricultura familiar en el agro argentino: una contribución al debate sobre el futuro del campesinado. European Review of Latin American and Caribbean Studies, (91), 49-70.

Pengue, W. (2004). Producción agro-exportadora e (in)seguridad alimentaria: El caso de la soja en Argentina. Revista Iberoamericana de Economía Ecológica, (1), 46-55.

Rearte, D. (2010). Situación actual y perspectiva de la producción de carne vacuna. Recuperado de http://inta.gob.ar/ situacionActual_\%20Prospectiva_produccion_\%20carnevacuna.\%20pdf

\section{territarias 30}

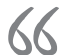

foque regional. Asociación Latinoamericana de Producción Animal, 19(3-4), 46-49.

Reboratti, C. (2006). La Argentina rural entre la modernización y la exclusión. En A. I. Geraiges de Lemos, M. Arroyo y M. L. Silveira América Latina: cidade, campo e turismo (pp. 175-187). San Pablo: Consejo Latinoamericano de Ciencias Sociales.

Rofman, A. (2012). El avance de la frontera agrícola en regiones extrapampeanas. Revista Voces en el Fénix. Recuperado de http://www.vocesenelfenix.com/ content/el-avance-de-la-fronteraagr \%C3 \%ADcola-en-regiones-extrapampeanas

Servicio Nacional de Sanidad y Calidad Agroalimentaria. (2013). Indicadores ganadería bovina. Recuperado de http://www.senasa.gov.ar/indicadores.php?in $=1$

Teubal, M. (2001). Globalización y nueva ruralidad en América Latina ¿Una nueva ruralidad en América Latina? Buenos Aires: Consejo Latinoamericano de Ciencias Sociales.

Torres, L. (2006). Formas de recordar y olvidar en Mendoza, Argentina. Revista Historia, Antropologia y Fuentes orales, (36), 113-138.

Tortosa, J. M. (comp.) (2011). Mal desarrollo y mal vivir. Pobreza y violencia a escala mundial. Quito: Editorial ABYAYALA.

Valenzuela, C. (2005). Transformaciones y conflictos en el agro chaqueño durante los 90. Articulaciones territoriales de 
una nueva racionalidad productiva. Mundo agrario, 5(10). Recuperado de http://www.scielo.org.ar/scielo. php? script=sci_arttext $\&$ pid $=S 1515$ $59942005000100002 \& \operatorname{lng}=$ es\&nrm $=$ iso

Viglizzo, E. F. (1994). El InTA frente al desafío del desarrollo agropecuario susten- table. En L. Verde y E. Viglizzo (eds). Desarrollo agropecuario sustentable (pp. 11-30). Buenos Aires: INTA-Indec. Viglizzo, F. y Jobbágy, E. (2010). Expansión de la frontera agropecuaria en Argentina y su impacto ecológico-ambiental. Buenos Aires: Ediciones Instituto Nacional de Tecnología Agropecuaria. 
